Article

\title{
Implementing and Monitoring Circular Business Models: An Analysis of Italian SMEs
}

\author{
Daniela M. Salvioni (D), Luisa Bosetti $*$ (D) and Tommaso Fornasari $(\mathbb{D}$ \\ Department of Economics and Management, University of Brescia, 25121 Brescia, BS, Italy; \\ daniela.salvioni@unibs.it (D.M.S.); tommaso.fornasari@unibs.it (T.F.) \\ * Correspondence: luisa.bosetti@unibs.it
}

Citation: Salvioni, D.M.; Bosetti, L.; Fornasari, T. Implementing and Monitoring Circular Business Models: An Analysis of Italian SMEs. Sustainability 2022, 14, 270. https:/ / doi.org/10.3390/su14010270

Academic Editor: David K. Ding

Received: 18 November 2021

Accepted: 23 December 2021

Published: 27 December 2021

Publisher's Note: MDPI stays neutral with regard to jurisdictional claims in published maps and institutional affiliations.

Copyright: (c) 2021 by the authors Licensee MDPI, Basel, Switzerland. This article is an open access article distributed under the terms and conditions of the Creative Commons Attribution (CC BY) license (https:// creativecommons.org/licenses/by/ $4.0 /)$.

\begin{abstract}
The transition from a linear to a circular economy (CE) is at the center of the debate among institutions, enterprises, practitioners, and scholars. Small- and medium-sized enterprises (SMEs), with their high presence in the business environment, play a pivotal role in the successful implementation of CE principles. Therefore, this paper aims to understand the state of the CE among Italian SMEs, considering both their different sizes and sectors. This study investigates CE knowledge and application, strategic relevance, benefits from and barriers to the transition towards circular business models, and the use of CE-related performance indicators in management control and external reporting. Through an online survey carried out in cooperation with the Italian Confederation of Craft Trades and Small- and Medium-Sized Enterprises (CNA), we collected primary data from 623 respondents. Findings revealed the existence of cultural, technological, market and financial barriers, which have hampered the adoption of circular practices among Italian SMEs. Poor understanding of CE potential, combined with difficulty in raising public and private funds to finance the transition from linear to circular, are the greatest problems. To overcome such issues, we recommend serious intervention by public institutions, trade and consumer associations, and the higher education system to develop a climate more favorable to the CE.
\end{abstract}

Keywords: circular economy; sustainability; SMEs; survey; awareness; benefits; barriers; circular economy-related KPIs; reporting on circular economy

\section{Introduction}

The circular economy (CE) is increasingly gaining traction among scholars, supranational political institutions, and practitioners, with obvious implications on corporate business models. In fact, on the one hand, the CE meets the need for companies to reduce their environmental impact [1-9]; on the other hand, it helps achieve sustainability of the planet, as encouraged by the Sustainable Development Goals (SDGs) included in the 2030 Agenda.

Since the industrial revolution, companies have favored the linear economic model, based on "take, make, and dispose", a pattern of consumption in which products are made using raw materials, purchased, used and, at the end of their life cycle, landfilled [10]. The consumption of resources and waste disposal connected to the actual demand for goods have made this traditional model unsustainable for the planet, creating an imbalance between resource supply and demand for goods [11].

Over the years, the international debate on protecting the planet and corporate sustainability [12,13], has emphasized the importance of closing material loops [14], pointing out the need to shift from a "take and discard" logic, typical of a linear economy [15], to a "reuse, recycle, and recover" logic, typical of the CE [16-21].

Corporate social responsibility and sustainability, accompanied by the increase in price volatility, the need to reduce the environmental impact of production, consumption, and disposal, lead to a rethinking of the business model in favor of a CE [22]. 
A CE reduces resource inputs and waste, emissions and energy losses, through design, maintenance, repair, reuse, regeneration, refurbishment, and recycling.

Socially responsible companies face new business models that focus on effective stakeholder relations and require an unprecedented alignment of technological and social factors. This epochal change reflects the improvement of the environmental impact of companies' activities and products, with responsible design that is based on renewable energy and the reduction in waste and toxic chemicals.

The need for a profound overhaul of production systems to guarantee a sustainable impact on growth is clear to everyone. Water-related and foodborne diseases, wildfires, salination, raised sea levels as well as extreme weather events such as drought, severe rainfall, storms and hurricanes [23] are just some of the effects of climate change produced by a model of development that has been pursued for years and has become unsustainable [24-26].

Climate change causes damage to multiple sources; whilst the direct consequences are clear, the indirect effects, which will become apparent in the coming years, could be even worse. Soil acidification and desertification, acid rain and the scarcity of clean water are rapidly spreading phenomena even in areas of the globe historically accustomed to enjoying only the benefits of traditional industrialization. The social consequences of the proliferation of such events will likely affect the full enjoyment of human rights, including the right to life, health, food, housing, an adequate standard of living, land and employment [27-31].

Currently, the only option to reverse this course is a rapid and effective transition to a more planet-friendly overall system, ranging from sustainable production systems to producing less waste, through a radical overhaul of individual habits. This necessarily requires a huge contribution by the business world, including all actors, in terms of size and geographical location, with a united effort by all countries, starting with those which, in the past, have made greater use of common resources [32].

To ensure the long-term growth of the industrial and productive system and the development of financial markets [33], through the creation of value for all shareholders and stakeholders [34], we need a transition to viable production systems, such as those of the CE.

Ferrero, Barilla and Lavazza constitute successful examples of large Italian groups engaged in the CE transition. Barilla recovers the bran resulting from the processing of cereals, to make it a raw material to produce paper for packaging. Lavazza cultivates mushrooms from coffee grounds and transforms coffee capsules, produced in biodegradable plastic, into compost. Ferrero uses hazelnut shells, deriving from its production processes, as a fuel to produce energy.

However, to be effective and to generate significant impacts on the planet, the shift from linear to circular business models must be comprehensive and not limited to just the biggest and most responsible companies.

Setting up a circular business involves the development of specific skills and sensitivities, together with a clear orientation towards social responsibility and sustainability. To function optimally, it also requires a specific configuration of existing and new capabilities. Corporate planning and strategy must be reviewed and action taken towards product/service innovation and development, as well as sourcing and manufacturing, sales and marketing. To fulfill their mission, companies need to reset their existing business models, reconsidering their development in relation to the conditions of circularity.

In the years to come, the growth of the world population will turn into increased demand for goods, which will result in a shortage of commodities. The CE, basing on reuse and recycle principles, could be an excellent answer to the scarcity of raw materials.

To date, many studies $[35,36]$ and concrete initiatives, such as those presented in Table 1, have tried to encourage the adoption of CE principles in big corporations, while just a few have promoted those principles among small- and medium-sized enterprises. 
Table 1. Significant initiatives of the CE.

\begin{tabular}{|c|c|}
\hline Initiative & Description \\
\hline The Circular Economy 100 [37] & $\begin{array}{l}\text { A program established to enable organizations to develop new opportunities and fulfill their } \\
\text { circular economy ambitions faster. It brings together companies, governments and cities, } \\
\text { academic institutions, emerging innovators, and affiliates in a unique multi-stakeholder platform. }\end{array}$ \\
\hline Kyoto Club [38] & $\begin{array}{l}\text { An organization devoted to the promotion of energy efficiency, renewable energy sources, waste } \\
\text { reduction and reuse of resources, sustainable mobility, and climate change. }\end{array}$ \\
\hline Circular Economy Club [39] & $\begin{array}{l}\text { An international network of the circular economy field, including professionals and organizations } \\
\text { with over } 280 \text { CEC local clubs in } 140 \text { countries. }\end{array}$ \\
\hline $\begin{array}{l}\text { European Circular Economy } \\
\text { Stakeholder Platform [40] }\end{array}$ & $\begin{array}{l}\text { A joint initiative by the European Commission and the European Economic and Social } \\
\text { Committee to promote the exchange of ideas and information on the CE. }\end{array}$ \\
\hline DigiCirc [41] & $\begin{array}{l}\text { A program to bring companies, public bodies, and researchers to work together to make our } \\
\text { economy more sustainable. }\end{array}$ \\
\hline
\end{tabular}

Therefore, this study will venture into a territory not yet sufficiently studied by academics: the knowledge and application of CE principles within small- and mediumsized enterprises [42-44] and consequent adoption of KPIs to establish objectives, monitor their achievement and inform stakeholders.

This paper investigates the state of the CE among Italian SMEs, considering both their different sizes and sectors. This study focuses on CE knowledge and application, strategic relevance, benefits from and barriers to the transition towards circular business models, and the use of CE-related performance indicators in management control and external reporting [45]. This paper helps scholars understand entrepreneurs' perspectives on the CE. Moreover, this study supports practitioners and managers in turning CE principles into practice. Finally, it clarifies in which specific areas government agencies, trade associations and NGOs engaged in the promotion of sustainability should take future actions to support the spread of the CE.

This paper is structured as follows: this introduction (Section 1); a review of the literature on the CE (Section 2); the methodology section (Section 3); results (Section 4); discussion (Section 5); conclusions, research limitations and future research directions (Section 6).

\section{Literature Review}

To provide a valid literature review, we adhere to three fundamental principles [46]: $i$. show our familiarity with the major contributions on the CE; $i$. identify the key issues in the research area and the gaps in the existing literature; iii. help the readers understand the principles and theories that have been used by the authors in different parts of this study.

The origin of the $\mathrm{CE}$ is not straightforward and shared by scholars, as it is based on a fragmented collection of ideas derived from different scientific fields [47] such as ecological economics, industrial ecology [48-51], cleaner production [52-55], eco-efficiency [56-58], resilience of socio-ecological systems and the Zero Emissions concept [59,60].

Among these different scientific backgrounds, the one that best fits with $\mathrm{CE}$ is ecological economics: an established science with a long tradition in recycling and related issues [61-65] and whose fundamental premise that the economic system is an open subsystem of Earth's ecological system with limited resources and environmental capability.

The debate over achieving sustainability of the planet, involving the highest political institutions in the world [66], has underlined the importance of the CE as one of the main instruments to achieve the goal of delivering a sustainable world for future generations. The United Nations have held a leading role in this field since the start of the new millennium: in 2000, they approved the Millennium Development Goals and, in 2015, they launched the ambitious project named the 2030 Agenda for Sustainable Development, which established the Sustainable Development Goals (SDGs). The call for a review of consolidated paradigms to create a more sustainable world has been broadly welcomed by the European Union, 
while Germany, Japan, and China are the countries in which the CE has longest been a topic of discussion [67].

At the non-governmental level, the most authoritative source on the $\mathrm{CE}$ is undoubtedly the Ellen MacArthur Foundation, which declares the need for "a new economic system in which we design out waste and pollution, keep products and materials in use, and regenerate natural systems" [68].

Studies on the CE date back to the end of the last century [69-73], but it is only in the last decade that scholars have been particularly interested in the phenomenon [74,75].

Despite the fluent literature on the $\mathrm{CE}$, scholars and institutions have not reached a unique definition of the concept [76,77]; however, the fundamental work of Kirchherr et al. [78] has brought some order to the subject. Table 2 contains the most relevant definitions of the $\mathrm{CE}$, in the opinion of the authors.

Table 2. Relevant definitions of the CE.

\begin{tabular}{c}
\hline Author \\
\hline $\begin{array}{c}\text { European Commission } \\
(2014)[79]\end{array}$ \\
\hline European Parliament (2015) [80] \\
\hline
\end{tabular}

Ellen MacArthur Foundation (2015) [81]

OECD (2016) [82]

Sauvé et al. (2016) [83]

Circular Academy (2017) [84]

Murray et al. (2017) [10]

"A development strategy that enables economic growth while optimising consumption of resources, deeply transforms production chains and consumption patterns, and redesigns industrial systems at the system level"

"The circular economy is a model of production and consumption, which involves sharing, leasing, reusing, repairing, refurbishing and recycling existing materials and products as long as possible. In this way, the life cycle of products is extended. In practice, it implies reducing waste to a minimum"

"The circular economy is one that is restorative and regenerative by design and aims to keep products, components, and materials at their highest utility and value at all times, distinguishing between technical and biological cycles. This new economic model seeks to ultimately decouple global economic development from finite resource consumption. It enables key policy objectives such as generating economic growth, creating jobs, and reducing environmental impacts, including carbon emissions"

"With an expected global population of 9 billion by 2030, including 3 billion middle-class consumers, future consumption demand will create unprecedented pressure on natural resources. The Forum reflected on the importance of the "circular economy" in decoupling economic growth and job creation from the use of natural resources. Turning the ambition of the SDGs into reality will require robust data to capture progress, ensure effective monitoring and provide evidence to inform decision making"

"Model of production and consumption of goods through closed loop material flows that internalize environmental externalities linked to virgin resource extraction and the generation of waste (including pollution)"

"A circular economy is a transformative economy redefining production and consumption patterns, inspired by ecosystems principles and restorative by design, which increases resilience, eliminates waste and creates shared value through an enhanced circulation of material and immaterial flows"

"We define the Circular Economy as a regenerative system in which resource input and waste, emission, and energy leakage are minimised by slowing, closing, and narrowing material and energy loops. This can be achieved through long-lasting design, maintenance, repair, reuse, remanufacturing, refurbishing, and recycling"

"The Circular Economy is an economic model wherein planning, resourcing, procurement, production and reprocessing are designed and managed, as both process and output, to maximize ecosystem functioning and human well-being"

"A circular economy describes an economic system that is based on business models which replace the 'end-of-life' concept with reducing, alternatively reusing, recycling and recovering materials in

Kirchherr et al. (2017) [78] production/distribution and consumption processes, thus operational at the micro level (products, companies, consumers), meso level (eco-industrial parks) and macro level (city, region, nation and beyond), with the aim to accomplish sustainable development, which implies creating environmental quality, economic prosperity and social equity, to the benefit of current and future generations"

"Circular Economy is a sustainable development initiative with the objective of reducing the societal production-consumption systems' linear material and energy throughput flows by applying materials cycles, renewable and cascade-type energy flows to the linear system. Circular economy promotes high value material cycles alongside more traditional recycling and develops systems approaches to the cooperation of producers, consumers, and other societal actors in sustainable development work"

Although there are dozens of definitions of the CE, we can group the studies and experiences of the CE into three levels: the micro level (companies and consumers) [85-89], the meso level (industrial districts and manufacturing networks) [90], and the macro level (societies, countries, and overall business systems) [91]. Our research focuses on the micro level. Following the logic that identifies several similarities between the different definitions 
of the $\mathrm{CE}$, we are able to establish certain common elements, such as those found by the Ellen MacArthur Foundation in the ReSOLVE framework: regenerate, share, optimize, loop, and exchange [81], as explained in Table 3.

Table 3. Characteristics of the ReSOLVE.

\begin{tabular}{|c|c|c|c|c|}
\hline Action & \multicolumn{4}{|c|}{ Description } \\
\hline Regenerate & \multicolumn{4}{|c|}{$\begin{array}{c}\text { Shift to renewable energy and materials; reclaim, retain, and restore health of ecosystems; return recovered } \\
\text { biological resources to the biosphere }\end{array}$} \\
\hline Share & \multicolumn{4}{|c|}{$\begin{array}{l}\text { Keep the product loop speed low and maximize the utilization of products by sharing them among users, } \\
\text { reusing them throughout their technical lifetime, and prolonging their life through maintenance, repair, and } \\
\text { design for durability }\end{array}$} \\
\hline Optimize & \multicolumn{4}{|c|}{ Increase the performance/efficiency of a product and remove waste in production and the supply chain } \\
\hline Loop & \multicolumn{4}{|c|}{$\begin{array}{l}\text { Keep components and materials in closed loops, and prioritize inner loops. In the case of finite materials, this } \\
\text { means remanufacturing products or components, and, as a last resort, recycling materials }\end{array}$} \\
\hline Virtualize & \multicolumn{4}{|c|}{ Dematerialize directly and indirectly } \\
\hline Exchange & \multicolumn{4}{|c|}{ Replace old materials with advanced non-renewable materials and apply new technologies } \\
\hline \multirow{2}{*}{\multicolumn{5}{|c|}{$\begin{array}{l}\text { Still, many authors share a type of framework, over and above different aspects of } \\
\text { the CE, known as the "R" frameworks [92]: the } 3 R s[3,93,94] \text {, the } 4 R s[95] \text {, the } 6 R s \text { [96], or } \\
\text { even the } 9 R s \text { [97] -and these are the most popular frameworks used in discussion of the } \\
\text { CE [98]. Each framework is based on different principles-reuse, repair, recycle, refurbish, } \\
\text { rethink, remanufacture, repurpose, recover, reduce and refuse-which the authors combine } \\
\text { in different ways, according to their research and discussion. For our purposes, we have } \\
\text { determined the hierarchy presented in Table } 4 \text {. } \\
\text { Table 4. The " } R \text { " framework. }\end{array}$}} \\
\hline & & & & \\
\hline & Framework & $4 R s$ & $6 R s$ & 9Rs \\
\hline & Strategies & $\begin{array}{l}\text { Reuse } \\
\text { Repair } \\
\text { Recycle } \\
\text { Refurbish }\end{array}$ & $\begin{array}{c}\text { Reuse } \\
\text { Repair } \\
\text { Recycle } \\
\text { Refurbish } \\
\text { Rethink } \\
\text { Remanufacture }\end{array}$ & $\begin{array}{c}\text { Reuse } \\
\text { Repair } \\
\text { Recycle } \\
\text { Refurbish } \\
\text { Rethink } \\
\text { Remanufacture } \\
\text { Repurpose } \\
\text { Recover } \\
\text { Reduce }\end{array}$ \\
\hline
\end{tabular}

The starting point of our hierarchy is the 3Rs: reuse (by another consumer of a discarded product which is still in good conditions and fulfils its original functions) combined with repair (or maintenance of a defective product so it can be used with its original functions) and recycle (processing materials to obtain the same or lower quality). The 4 Rs add refurbish (restoring and updating an old product), while the $6 R$ s also consider rethink (making product use more intensive) and remanufacture (using parts of a discarded product in a new one with the same function). The $9 R s$ are completed with repurpose (using a discarded product or its part in a new product with a different function), recover (incineration of material with energy recovery) and reduce (increasing efficiency in product manufacture or use by consuming fewer natural resources and material). For completeness, we also mention the concept of refuse (making a product redundant by abandoning its function or by offering the same function with a radically different product), indicated in the model by Potting at al. [99], from which the definitions contained in this paragraph are drawn.

Among the various definitions and frameworks available, our research follows the direction set by the European Parliament in 2015, with the adoption of the First Circular 
Economy Action Plan by the European Commission. The objectives of this initiative were to stimulate the transition to a more sustainable model of industrial development, boost global competitiveness and create new jobs. The identified concrete and ambitious actions include responsible production and consumption, waste management, the market for secondary raw materials, and a revised legislative proposal on waste [100].

In 2019, the European Commission published a comprehensive report on the implementation of the action plan with the purpose of achieving climate neutrality and minimize the pressure on natural and freshwater resources.

Then, in 2020, the European Commission adopted the New Circular Economy Action Plan (CEAP) with the aim of reducing pressure on natural resources and creating sustainable growth. The new action plan targets product design, promotes the CE, encourages sustainable consumption and aims to prevent waste and ensure that the resources used are kept in the EU economy for as long as possible [101].

The commitment and provisions of the EU concern all companies operating in the Member States. Whilst small- and medium-sized enterprises represent $99 \%$ of all businesses in the EU [102], much of the scientific research focuses on the $1 \%$ of big corporations. For this reason, we considered it appropriate to focus on SMEs.

In the EU legislation, the characteristics of small- and medium-size enterprises are included in Recommendation 2003/361, which define them as enterprises with: $i$. fewer than 250 employees and ii. annual turnover not exceeding EUR 50 million or an annual balance sheet total not exceeding EUR 43 million. By their very nature, SMEs are often characterized by undercapitalization, a lack of highly skilled staff and low investment in research and technological innovation [103-106]. SMEs are usually resource-constrained, in terms of time, staff, and economic resources, compared to larger companies, and they are less likely to undertake transformational changes; moreover, they often have poor awareness of their impact on stakeholders [107-109].

Despite the limits just identified, SMEs have certain strengths [110-112], such as flexibility, creativity and speedy decision-making, which make them the ideal candidates to guide the transition to a CE. Indeed, the path to a more sustainable production system will not reach its targets if it is limited to big corporations. In the European Union, for example, SMEs generate $56 \%$ of the total turnover of companies; therefore, their contribution towards an effective transition to a sustainable production system for the planet, through the CE, is not negligible.

As specifically concerns Italy, the existing studies on the CE mainly refer to large companies $[113,114]$, which suggests that SMEs play a merely residual role in the transition towards the desired new business system. Consequently, a broad analysis of the CE in Italian SMEs is appropriate to fill this gap.

The large number of SMEs operating in Italy and their consequent environmental impact stimulate scholars to in-depth analyze the EC phenomenon among enterprises. Therefore, this paper aims to fill in the gap, providing tools to design possible interventions and promoting the spread of best practices.

To investigate the state of the CE among Italian SMEs, considering both their different sizes and sectors, we conducted quantitative research to address specifically the following research questions:

- What is the degree of awareness and knowledge about the CE in SMEs?

- Do SMEs attach strategic importance to the CE?

- Which CE practices are applied in SMEs?

- What are the benefits experienced by SMEs from the implementation of CE practices? Additionaly, what is the opinion of SMEs on the potential of the CE?

- What are the barriers to adopting a CE strategy in SMEs?

- Do SMEs use CE-related KPIs to establish corporate and individual targets and to inform stakeholders about the performance achieved?

This study follows the suggestions for future research provided, among others, by: Mura et al. [13], who propose considering the implementation of a CE in different sectors 
(e.g., manufacturing and service-based enterprises); Fonseca et al. [115], who suggest a country-based investigation; Kirchherr et al. [116], who underline the importance of identifying the different barriers to the CE depending on the sector; Rincón-Moreno et al. [117], who recommend cross-sector research on CE performance indicators; and Ferasso et al. [118] who underline the need for studies on processes, such as management control, subject to organizational changes in circular business models.

\section{Materials and Methods}

As mentioned in the previous section of this paper, the CE in Italian SMEs is still a relatively unexplored field. The need to collect primary data [119] on a significant number of companies led to the choice of conducting an online survey, rather than focusing on companies' reports [45]. This type of research tool presents several advantages [120-122]: first, a web-based questionnaire has the potential to reach many respondents at a very low cost; second, an online questionnaire can guarantee a high response rate because it can be completed at the respondent's convenience (within the deadline communicated by the researchers) using a simple device; third, a computer-administered survey enables automatic branching, with filter questions so that respondents see only the questions that are relevant to them, according to their previous answers.

The questionnaire we used for our research was composed of 20 closed-ended questions and attitude scales, some of which covering multiple items. Closed-ended questions and attitude scales, such as Likert-type scales [120], are very common in questionnaires, because they make it easier to summarize and compare responses than open-ended questions [115,123-125]; moreover, they reduce the risk of inappropriate and ambiguous responses, as may occur when respondents are left completely free to express themselves [120].

To prepare the questionnaire, we conducted an extensive literature review $[13,34,64$, 75,109,117-119], which permitted us to identify the elements of the CE relevant to SMEs. Questions on these elements were organized in a first draft of the questionnaire, which was submitted to the Environmental Policies Department of CNA, the Italian Confederation of Craft Trades and Small- and Medium-Sized Enterprises, to gather comments, observations, and suggestions. The CNA provided invaluable support in our research, as one of the most representative associations of Italian SMEs with a membership base including artisans, business owners, professionals, self-employed and small and micro-businesses in all services and industrial sectors all over the country.

The CNA's direct knowledge of Italian SMEs allowed an in-depth review of the draft questionnaire: the structure, contents and sequence of the questions were assessed by the CNA and partially reformulated, regrouped and improved to assure their completeness, adequacy and clarity. The CNA suggested, and we adopted, terms potential respondents would be more familiar with, and the use of a less technical language. This revision made the questionnaire more consistent with the literacy level of potential respondents [120] and enabled us to avoid pre-testing the questionnaire on a small sample of businesses [126].

To be sure all the respondents shared our concept of the $\mathrm{CE}$, the questionnaire began with the well-known definition of the CE adopted by the European Parliament in 2015 and proposed in Table 2.

After three initial questions on the characteristics of the organization (location, sector and size), the questionnaire addressed the following aspects: awareness and knowledge of the $\mathrm{CE}$ (two questions); strategic importance of the $\mathrm{CE}$ (one question); implementation of a $\mathrm{CE}$ (six questions); benefits obtained and perceived (two questions, articulated in many items); barriers to the adoption of a CE (one question); use of KPIs on the CE (four questions, divided into several sub-questions) and transparency on CE performance (one question).

Certain questions allowed multiple responses. The questionnaire also included some filter questions that automatically guided respondents to the next relevant question, based on the answer to the previous question. 
The questionnaire was available online from 5 to 19 July 2021. On the initiative of the CNA Environmental Policies Department, the survey was widely publicized in the CNA newsletter and on its official social networks to reach as many associated businesses as possible. A reminder to complete the survey was also posted ten days after the first announcement. In addition, the CNA's regional and territorial offices, which usually have closer contact with members, were invited to promote the questionnaire further through their websites and mailing lists.

For the CNA, this was the first time it took part in research to explore the actions of its members in relation to the $\mathrm{CE}$, whereas it had already conducted surveys on sustainability. The questionnaire on the $\mathrm{CE}$ was completed by 623 respondents, a number in accordance with previous surveys carried out by the CNA and higher than other recent countrybased academic surveys on the CE (see, for example, Fonseca et al. [115], who analyzed 99 Portuguese organizations; Oncioiu et al. [42], who considered 384 Romanian SMEs; Mura et al. [13] who focused on 254 Italian SMEs; and Holzer et al. [127], who investigated 183 Austrian SMEs).

\section{Research Protocol}

A research protocol is a detailed plan of a study. Typically, the formalization of a research protocol is an essential step in health research, which is carried out by a team of investigators and requires clinical trials of pharmaceuticals, medical devices and other medical products [128-130]. However, a written protocol is useful in any field of research, including business and management studies, because it forces the researchers to carefully design all aspects of the study at the beginning of their project. Moreover, if the study is developed by a research group, the protocol clarifies the contribution expected from every team member in different stages of research and it provides the necessary guidelines all the participants must comply with.

To properly plan and implement our research program, we adopted a specific research protocol, consisting in a long and detailed document, the main parts of which we have already described in this paper. Table 5 summarizes the research protocol that led our study, specifying which activities had to be done in each stage, how many researchers had to be involved, and in which stages the researchers would have required the cooperation of the CNA.

Since the very early stages of research, we considered how to ensure data quality, which depends on reliability of measurement and validity of survey information [131].

Reliability concerns consistency of results obtained at different time, by different researchers/observers, and in different occasions and it is usually assessed through the testretest method [120]. However, the cooperation of CNA experts in the field of sustainability and CE allowed us to avoid the test-retest. In fact, they meticulously checked all closedended questions included in our survey questionnaire to spot glaring flaws, which would have badly affected consistency of findings. Moreover, the use of the internet to administer the questionnaire and the presence of only closed-ended questions ensured high objectivity and prevented accidental, inconsistent behavior on the part of the researchers, which could have determined poor reliability.

Validity is the extent to which a test measures what it is intended to measure [132]. Validity relates to the accuracy of a measure and its subsequent suitability to support the conclusions. To ensure validity of survey information, we based our questionnaire on established theory and findings of previous studies. Moreover, we carefully selected the questions to submit to the participants and we adopted precise wording.

We paid particular attention to construct validity. A construct is an abstract concept that is deliberately created to represent a collection of concrete forms of behavior [120]. Whereas a construct cannot be directly observed, it can be measured by concentrating on other indicators associated with it. As the construct of our study was the companies' inclination to the $\mathrm{CE}$, we assumed $\mathrm{CE}$ knowledge, $\mathrm{CE}$ application, $\mathrm{CE}$ strategic relevance, benefits from $\mathrm{CE}$, barriers to the $\mathrm{CE}$ transition, and use of CE-related KPIs as indicators of 
the construct. Therefore, every question we inserted in the questionnaire focused on one of these topics.

Table 5. Research protocol.

\begin{tabular}{|c|c|c|}
\hline $\begin{array}{l}\text { Rationale for } \\
\text { research }\end{array}$ & $\begin{array}{l}\text { - Aim of this study: to investigate the state of the CE } \\
\text { among Italian SMEs, considering both their } \\
\text { different sizes and sectors. } \\
\text { - } \quad \text { Literature review, aimed at understanding where } \\
\text { to position our study. } \\
\text { Literature gap to be filled: specific studies on the } \\
\text { adoption of CE principles in SMEs are still rare; in } \\
\text { particular, Italian SMEs have been largely } \\
\text { investigated, but not in respect of their inclination } \\
\text { to implement CE practices and the subsequent } \\
\text { need for improving CE-related } \\
\text { performance indicators. }\end{array}$ & $\begin{array}{l}\text { - All the researchers involved } \\
\text { in conceptualization. } \\
\text { - Two researchers involved in literature review. }\end{array}$ \\
\hline Objectives & Identification of simple, specific research questions. & - $\quad$ Two researchers involved in objective setting. \\
\hline Methodology & $\begin{array}{l}\text { Selection of the sample: Italian SMEs (specifically, } \\
\text { the CNA members). } \\
\text { Selection of the method: quantitative research } \\
\text { based on a questionnaire survey, administered } \\
\text { through the internet. } \\
\text { Literature review, aimed at identifying all aspects } \\
\text { to investigate through the questionnaire. } \\
\text { - Preparation of the questionnaire. } \\
\text { - Meetings with the CNA's experts to review and } \\
\text { improve the questionnaire. } \\
\text { Construct validity, assessed through literature } \\
\text { review and CNA experts' judgement on the } \\
\text { questionnaire structure and content. } \\
\text { Reliability, ensured by the cooperation of the CNA } \\
\text { in distributing the online questionnaire to } \\
\text { its members. }\end{array}$ & $\begin{array}{l}\text { One researcher involved in defining } \\
\text { the methodology. } \\
\text { Two researchers involved in preparing and } \\
\text { revising the questionnaire. } \\
\text { Cooperation of the CNA's experts in the } \\
\text { review and improvement of } \\
\text { the questionnaire. }\end{array}$ \\
\hline $\begin{array}{l}\text { Data } \\
\text { management and } \\
\text { analysis }\end{array}$ & $\begin{array}{l}\text { - Data verification. } \\
\text { - } \quad \text { Data processing supported by Excel. } \\
\text { survaration of tables and figures to represent the } \\
\text { sults. }\end{array}$ & $\begin{array}{l}\text { - Cooperation of the CNA's ICT staff in } \\
\text { processing data using Excel. } \\
\text { - Two researchers involved in data verification. } \\
\text { One researcher involved in preparing tables } \\
\text { and figures. }\end{array}$ \\
\hline $\begin{array}{c}\text { Ethical } \\
\text { considerations }\end{array}$ & $\begin{array}{l}\text { - Need to protect the privacy of respondents, in } \\
\text { compliance with Regulation (EU) 2016/679 } \\
\text { (GDPR) requirements. }\end{array}$ & \\
\hline
\end{tabular}

Construct validity derives evidence from other types of validity, including face validity and content validity [133]. Face validity consists in a subjective judgement of the questionnaire, typically expressed by the researchers considering the relevance, reasonability, unambiguity and clearness of the items [134]. Face validity is an informal assessment of how the content seems to be on the surface, so it is considered a weak form of validity that requires further evaluation. For this reason, we also examined content validity, which relates to the representativeness of all aspects of the construct [135]. As our survey covered all significant aspects of the companies' inclination to the $\mathrm{CE}$ that had emerged from an extensive literature review and it was positively assessed by CNA experts, it specifically achieved content validity.

However, some threat to validity still remains. Among others, evaluation apprehension may have affected the answers to the questionnaire. Evaluation apprehension is something similar to the subject effect (also known as the Hawthorne effect) [136] in 
experimental research. According to the so called subject effect, people who are conscious of being studied change their behavior to perform better and look smarter. In a survey design like ours, the answers might reflect the wish of some respondents to appear more interested and engaged in the $\mathrm{CE}$ transition than they really were.

\section{Results}

This section presents the results of the survey, starting with the sample composition. This is followed by a description of the results, highlighting the links with the size (micro, small and medium) and sector (manufacturing, construction, and services) of the SMEs.

\subsection{Characteristics of Study Participants}

Figure 1 shows the composition of the investigated sample, according to three criteria: location, number of employees and activity sector.

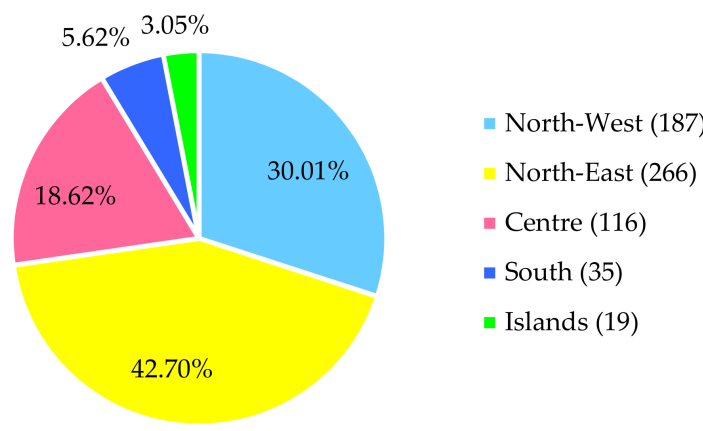

(a)

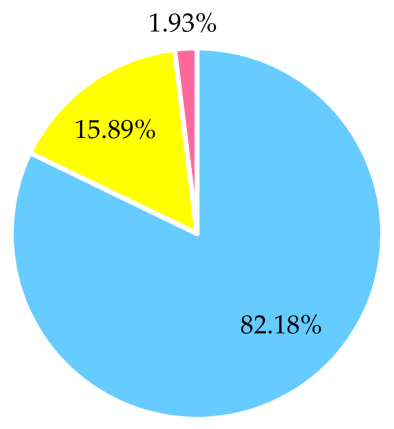

- 1 - 9 (micro-enterprises) (512)

- $10-49$ (small enterprises) (99)

- $50-249$ (medium enterprises) (12)

(b)

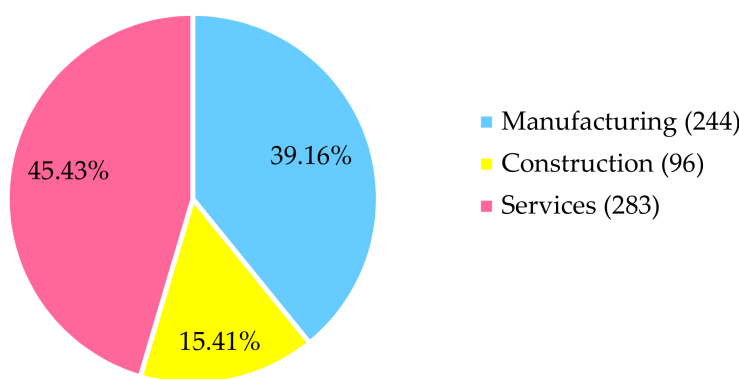

(c)

Figure 1. Sample structure: (a) location; (b) number of employees; (c) sector.

Most of the 623 SMEs that completed the questionnaire were located in Northern Italy: more specifically, $187(30.01 \%)$ were located in the North-West and $266(42.70 \%)$ in the 
North-East; 116 businesses (18.62\%) were located in Central Italy; 35 enterprises (5.62\%) were based in Southern Italy and 19 (3.05\%) on Italian islands. This composition partly reflects the Italian regional distribution of SMEs that are sensitive to the environmental impact of their activities, according to the ISTAT permanent census [137]. However, while the ISTAT census located only $51 \%$ of these SMEs in the north, our survey obtained a higher percentage of responses from that area $(72.71 \%)$. This could be due to a more intensive promotion of $\mathrm{CE}$ practices by the local CNA offices operating in northern regions, and their effective contribution in the dissemination of our questionnaire.

As concerns the staff size: 512 respondents representing $82.18 \%$ of the sample we analyzed were micro-businesses with fewer than 10 employees; 99 respondents $(15.89 \%)$ were small businesses with 10-49 employees; while the remaining 12 respondents $(1.93 \%)$ were medium enterprises with 50-249 employees. The predominance of micro-businesses in surveys concerning the $\mathrm{CE}$ is not new in the literature: micro-enterprises represented almost the $80 \%$ of the sample investigated by Mura et al. [13] with reference to the situation in Italy, and $89 \%$ of the sample analyzed by Oncioiu et al. [42] in Romania.

Regarding the sector of activity, 244 SMEs operated in manufacturing (39.16\%), 96 in construction (15.41\%) and 283 in services (45.43\%).

\subsection{Knowledge and Awareness of the CE Concept}

The first matter to be investigated was the respondents' knowledge and awareness of the $\mathrm{CE}$. Respondents were asked to assess their knowledge of the $\mathrm{CE}$ as accurate, average, or modest (Table 6).

Table 6. Respondents' self-assessment in knowledge of the CE.

\begin{tabular}{|c|c|c|c|c|c|c|c|c|c|c|c|c|c|c|}
\hline \multirow{2}{*}{ CE Knowledge } & \multicolumn{2}{|c|}{ Total } & \multicolumn{2}{|c|}{ Micro } & \multicolumn{2}{|c|}{ Small } & \multicolumn{2}{|c|}{ Medium } & \multicolumn{2}{|c|}{ Manufacturing } & \multicolumn{2}{|c|}{ Construction } & \multicolumn{2}{|c|}{ Services } \\
\hline & No. & $\%$ & No. & $\%$ & No. & $\%$ & No. & $\%$ & No. & $\%$ & No. & $\%$ & No. & $\%$ \\
\hline Accurate & 55 & $8.83 \%$ & 44 & $8.59 \%$ & 8 & $8.08 \%$ & 3 & $25.00 \%$ & 20 & $8.20 \%$ & 7 & $7.29 \%$ & 28 & $9.89 \%$ \\
\hline Average & 263 & $42.22 \%$ & 205 & $40.04 \%$ & 50 & $50.51 \%$ & 8 & $66.67 \%$ & 111 & $45.49 \%$ & 47 & $48.96 \%$ & 105 & $37.10 \%$ \\
\hline Modest & 305 & $48.96 \%$ & 263 & $51.37 \%$ & 41 & $41.41 \%$ & 1 & $8.33 \%$ & 113 & $46.31 \%$ & 42 & $43.75 \%$ & 150 & $53.00 \%$ \\
\hline Total & 623 & $100 \%$ & 512 & $100 \%$ & 99 & $100 \%$ & 12 & $100 \%$ & 244 & $100 \%$ & 96 & $100 \%$ & 283 & $100 \%$ \\
\hline
\end{tabular}

Only $8.83 \%$ of the entire sample declared that they have accurate knowledge of the CE, whereas $42.22 \%$ assessed it as average; however, the most common response was modest knowledge (48.96\%).

The degree of knowledge of the $\mathrm{CE}$ seems to be linked to the size of the business: in medium-sized enterprises, modest knowledge is much rarer (8.33\%) than in small (41.41\%) and micro $(51.37 \%)$ enterprises. On the other hand, $66.67 \%$ of respondents belonging to medium enterprises declared that they have average knowledge of the $\mathrm{CE}$, and $25 \%$ considered themselves to have accurate knowledge. This is probably due to the greater complexity of processes implemented in medium-sized enterprises than in the two other groups, which usually requires a larger workforce including higher qualified employees.

In terms of activity sector, accurate knowledge of the $\mathrm{CE}$ was declared in similar proportions in manufacturing $(8.20 \%)$, construction $(7.29 \%)$ and services $(9.89 \%)$. SMEs operating in services had the highest percentage of respondents with modest knowledge of the CE (53\%), while average knowledge was slightly more frequent in construction (48.96\%) than in manufacturing $(45.49 \%)$. It is probable that the implementation of processes involving the use or transformation of raw materials, which can have significant environmental impacts, stimulated the development of knowledge of the CE.

According to our survey, business experience is the most common way knowledge of the $\mathrm{CE}$ is acquired, regardless of the enterprise size and sector, as stated by 156 respondents of the 298 who answered this specific question. In addition, 49 respondents mentioned training and information by trade associations, and 46 cited higher education, university and other advanced courses as sources of knowledge on the CE. Finally, 98 respondents resorted to other means, such as individual and autonomous learning (Table 7). 
Table 7. How respondents acquired their knowledge of the CE.

\begin{tabular}{|c|c|c|c|c|c|c|c|c|c|c|c|c|c|c|}
\hline \multirow{2}{*}{$\begin{array}{c}\text { Acquisition of Knowledge } \\
\text { on the } C E^{1}\end{array}$} & \multicolumn{2}{|c|}{ Total } & \multicolumn{2}{|c|}{ Micro } & \multicolumn{2}{|c|}{ Small } & \multicolumn{2}{|c|}{ Medium } & \multicolumn{2}{|c|}{ Manufacturing } & \multicolumn{2}{|c|}{ Construction } & \multicolumn{2}{|c|}{ Services } \\
\hline & No. & $\%$ & No. & $\%$ & No. & $\%$ & No. & $\%$ & No. & $\%$ & No. & $\%$ & No. & $\%$ \\
\hline Business experience & 156 & $52.35 \%$ & 68 & $54.84 \%$ & 29 & $58.00 \%$ & 59 & $47.58 \%$ & 118 & $50.86 \%$ & 33 & $57.89 \%$ & 5 & $55.56 \%$ \\
\hline $\begin{array}{l}\text { Training and information } \\
\text { promoted by trade associations }\end{array}$ & 49 & $16.44 \%$ & 19 & $15.32 \%$ & 11 & $22.00 \%$ & 19 & $15.32 \%$ & 35 & $15.09 \%$ & 13 & $22.81 \%$ & 1 & $11.11 \%$ \\
\hline $\begin{array}{l}\text { Higher education, university, } \\
\text { advanced courses }\end{array}$ & 46 & $15.44 \%$ & 15 & $12.10 \%$ & 7 & $14.00 \%$ & 24 & $19.35 \%$ & 32 & $13.79 \%$ & 11 & $19.30 \%$ & 3 & $33.33 \%$ \\
\hline Other & 98 & $32.89 \%$ & 42 & $33.87 \%$ & 12 & $24.00 \%$ & 44 & $35.48 \%$ & 82 & $35.34 \%$ & 13 & $22.81 \%$ & 3 & $33.33 \%$ \\
\hline
\end{tabular}

${ }^{1}$ One or more options allowed. Percentages based on the number of respondents to the question (total: 298; micro: 232; small: 57; medium: 9; manufacturing: 124; construction: 50; services: 124).

\subsection{Strategic Importance of the $C E$}

As shown in Table 8, 298 respondents expressed their opinion on the strategic importance of the $\mathrm{CE}$ for their business. Overall, the answers were equally divided into those who agreed (50\%) and those who disagreed (50\%) with the strategic importance of the CE. Respondents from the construction sector were exactly divided between agreement and disagreement, unlike the other sectors, where there was either a tendency to agree with strategic role of the $\mathrm{CE}$, as in the services sector $(53.23 \%)$, or a tendency to disagree with the strategic importance of the CE for enterprises in manufacturing $(53.23 \%)$.

Table 8. Strategic importance of the CE.

\begin{tabular}{|c|c|c|c|c|c|c|c|c|c|c|c|c|c|c|}
\hline \multirow{2}{*}{$\begin{array}{c}\text { Strategic Importance } \\
\text { of the CE }\end{array}$} & \multicolumn{2}{|c|}{ Total } & \multicolumn{2}{|c|}{ Micro } & \multicolumn{2}{|c|}{ Small } & \multicolumn{2}{|c|}{ Medium } & \multicolumn{2}{|c|}{ Manufacturing } & \multicolumn{2}{|c|}{ Construction } & \multicolumn{2}{|c|}{ Services } \\
\hline & No. & $\%$ & No. & $\%$ & No. & $\%$ & No. & $\%$ & No. & $\%$ & No. & $\%$ & No. & $\%$ \\
\hline Yes & 149 & $50.00 \%$ & 113 & $48.71 \%$ & 31 & $54.39 \%$ & 5 & $55.56 \%$ & 58 & $46.77 \%$ & 25 & $50.00 \%$ & 66 & $53.23 \%$ \\
\hline No & 149 & $50.00 \%$ & 119 & $51.29 \%$ & 26 & $45.61 \%$ & 4 & $44.44 \%$ & 66 & $53.23 \%$ & 25 & $50.00 \%$ & 58 & $46.77 \%$ \\
\hline Total & 298 & $100 \%$ & 232 & $100 \%$ & 57 & $100 \%$ & 9 & $100 \%$ & 124 & $100 \%$ & 50 & $100 \%$ & 124 & $100 \%$ \\
\hline
\end{tabular}

The recognition of the strategic role of the $\mathrm{CE}$ seems to be correlated to the size of the company: the larger the business, the greater the recognition.

\subsection{Implementation of CE Practices}

The survey also investigated the actual implementation of $\mathrm{CE}$ practices in the Italian SMEs that completed the questionnaire (Table 9).

Table 9. Implementation of CE practices.

\begin{tabular}{|c|c|c|c|c|c|c|c|c|c|c|c|c|c|c|}
\hline \multirow{2}{*}{ Years of Experience } & \multicolumn{2}{|c|}{ Total } & \multicolumn{2}{|c|}{ Micro } & \multicolumn{2}{|c|}{ Small } & \multicolumn{2}{|c|}{ Medium } & \multicolumn{2}{|c|}{ Manufacturing } & \multicolumn{2}{|c|}{ Construction } & \multicolumn{2}{|c|}{ Services } \\
\hline & No. & $\%$ & No. & $\%$ & No. & $\%$ & No. & $\%$ & No. & $\%$ & No. & $\%$ & No. & $\%$ \\
\hline 1 year & 22 & $3.89 \%$ & 15 & $3.23 \%$ & 7 & $7.69 \%$ & 0 & $0.00 \%$ & 11 & $5.00 \%$ & 3 & $3.45 \%$ & 8 & $3.09 \%$ \\
\hline $2-3$ years & 45 & $7.95 \%$ & 32 & $6.88 \%$ & 10 & $10.99 \%$ & 3 & $30.00 \%$ & 15 & $6.82 \%$ & 9 & $10.34 \%$ & 21 & $8.11 \%$ \\
\hline 4-5 years & 27 & $4.77 \%$ & 21 & $4.52 \%$ & 6 & $6.59 \%$ & 0 & $0.00 \%$ & 15 & $6.82 \%$ & 2 & $2.30 \%$ & 10 & $3.86 \%$ \\
\hline$>5$ years & 77 & $13.60 \%$ & 58 & $12.47 \%$ & 18 & $19.78 \%$ & 1 & $10.00 \%$ & 34 & $15.45 \%$ & 9 & $10.34 \%$ & 34 & $13.13 \%$ \\
\hline CE will be introduced soon & 75 & $13.25 \%$ & 56 & $12.04 \%$ & 16 & $17.58 \%$ & 3 & $30.00 \%$ & 38 & $17.27 \%$ & 11 & $12.64 \%$ & 26 & $10.04 \%$ \\
\hline Not considering introducing CE & 320 & $56.54 \%$ & 283 & $60.86 \%$ & 34 & $37.36 \%$ & 3 & $30.00 \%$ & 107 & $48.64 \%$ & 53 & $60.92 \%$ & 160 & $61.78 \%$ \\
\hline Total & 566 & $100 \%$ & 465 & $100 \%$ & 91 & $100 \%$ & 10 & $100 \%$ & 220 & $100 \%$ & 87 & $100 \%$ & 259 & $100 \%$ \\
\hline
\end{tabular}

Only 171 respondents managed, or were employed by, a business that had already implemented CE processes; of these, 77 were enterprises with over five years of experience in CE practices $(13.60 \%$, a percentage much lower than in Romania, where it reached $62.8 \%$ [42]). The survey also revealed that 75 businesses intended to implement CE actions in the short term. On the other hand, 320 businesses representing $56.54 \%$ of the 566 respondents were not even considering the introduction of the $\mathrm{CE}$ in their activities. In general, the picture emerging from the survey contained contrasting elements: $\mathrm{CE}$ was a recent innovation in about one third of the SME respondents and had aroused interest in some others, but there was still large room for improvement in more than half of the sample.

Such scarce involvement was more frequent in services $(61.78 \%)$ and construction $(60.92 \%)$ than in manufacturing $(48.64 \%)$. Furthermore, the investigation proved that CE processes were less widespread in micro-businesses than in small- and medium-sized 
enterprises, and that micro-businesses were also significantly less prepared to implement CE practices within the short term.

As illustrated in Table 10, the investigation focused on three principal CE practices, which can be associated with one or more elements of the " $\mathrm{R}$ " framework.

Table 10. Implementation of CE practices.

\begin{tabular}{|c|c|c|c|c|c|c|c|c|c|c|c|c|c|c|}
\hline & \multicolumn{2}{|c|}{ Total } & \multicolumn{2}{|c|}{ Micro } & \multicolumn{2}{|c|}{ Small } & \multicolumn{2}{|c|}{ Medium } & \multicolumn{2}{|c|}{ Manufacturing } & \multicolumn{2}{|c|}{ Construction } & \multicolumn{2}{|c|}{ Services } \\
\hline & No. & $\%$ & No. & $\%$ & No. & $\%$ & No. & $\%$ & No. & $\%$ & No. & $\%$ & No. & $\%$ \\
\hline \multicolumn{15}{|c|}{ Internal recovery of materials in production processes (reuse, recycle, recover) } \\
\hline Yes & 93 & $60.00 \%$ & 61 & $54.95 \%$ & 30 & $75.00 \%$ & 2 & $50.00 \%$ & 43 & $60.56 \%$ & 12 & $60.00 \%$ & 38 & $59.38 \%$ \\
\hline Will do soon & 26 & $16.77 \%$ & 21 & $18.92 \%$ & 4 & $10.00 \%$ & 1 & $25.00 \%$ & 13 & $18.31 \%$ & 5 & $25.00 \%$ & 8 & $12.50 \%$ \\
\hline No, and not considering in short term & 36 & $23.23 \%$ & 29 & $26.13 \%$ & 6 & $15.00 \%$ & 1 & $25.00 \%$ & 15 & $21.13 \%$ & 3 & $15.00 \%$ & 18 & $28.13 \%$ \\
\hline Total & 155 & $100 \%$ & 111 & $100 \%$ & 40 & $100 \%$ & 4 & $100 \%$ & 71 & $100 \%$ & 20 & $100 \%$ & 64 & $100 \%$ \\
\hline \multicolumn{15}{|c|}{ Purchase of recycled materials or products (reduce) } \\
\hline Yes & 85 & $55.19 \%$ & 58 & $52.25 \%$ & 23 & $58.97 \%$ & 4 & $100.00 \%$ & 35 & $50.00 \%$ & 8 & $40.00 \%$ & 42 & $65.63 \%$ \\
\hline Will do soon & 37 & $24.03 \%$ & 29 & $26.13 \%$ & 8 & $20.51 \%$ & 0 & $0.00 \%$ & 22 & $31.43 \%$ & 6 & $30.00 \%$ & 9 & $14.06 \%$ \\
\hline No, and not considering in short term & 32 & $20.78 \%$ & 24 & $21.62 \%$ & 8 & $20.51 \%$ & 0 & $0.00 \%$ & 13 & $18.57 \%$ & 6 & $30.00 \%$ & 13 & $20.31 \%$ \\
\hline Total & 154 & $100 \%$ & 111 & $100 \%$ & 39 & $100 \%$ & 4 & $100 \%$ & 70 & $100 \%$ & 20 & $100 \%$ & 64 & $100 \%$ \\
\hline \multicolumn{15}{|c|}{ Redesign of processes, products and services according to CE principles (refuse) } \\
\hline Redesign of production processes & 46 & $32.39 \%$ & 27 & $26.47 \%$ & 19 & $51.35 \%$ & 0 & $0.00 \%$ & 32 & $47.76 \%$ & 3 & $15.79 \%$ & 11 & $19.64 \%$ \\
\hline Redesign of products and services & 53 & $37.32 \%$ & 43 & $42.16 \%$ & 8 & $21.62 \%$ & 2 & $66.67 \%$ & 12 & $17.91 \%$ & 10 & $52.63 \%$ & 31 & $55.36 \%$ \\
\hline Will do soon & 22 & $15.49 \%$ & 16 & $15.69 \%$ & 5 & $13.51 \%$ & 1 & $33.33 \%$ & 11 & $16.42 \%$ & 5 & $26.32 \%$ & 6 & $10.71 \%$ \\
\hline No, and not considering in short term & 21 & $14.79 \%$ & 16 & $15.69 \%$ & 5 & $13.51 \%$ & 0 & $0.00 \%$ & 12 & $17.91 \%$ & 1 & $5.26 \%$ & 8 & $14.29 \%$ \\
\hline Total & 142 & $100 \%$ & 102 & $100 \%$ & 37 & $100 \%$ & 3 & $100 \%$ & 67 & $100 \%$ & 19 & $100 \%$ & 56 & $100 \%$ \\
\hline
\end{tabular}

First, we considered the internal recovery of materials in production processes. Being implemented in 93 out of the 155 respondent enterprises (60\%), regardless of their sector, this CE practice was the one most applied at the time of the survey and it was about to be introduced by a further 26 respondents $(16.77 \%)$. Moreover, it was already largely adopted in small businesses $(75 \%)$. In detail, the internal recovery of materials includes

- Reuse of packaging and production off-cuts, a practice implemented in 54 companies, with the highest frequency in the manufacturing sector $(66.67 \%)$ and in small businesses $(65.2 \%)$;

- Recycle of waste, a process in progress in 50 SMEs, especially in the construction sector $(58.33 \%)$ and in micro-businesses $(57.38 \%)$;

- Energy recovery: incineration of residues for energy production, an uncommon operation implemented by only 11 enterprises, none of medium size. A similar result was obtained by Oncioiu et al. [42] for the Romanian context, where only $2.64 \%$ of the SMEs investigated had turned waste into energy.

We also investigated the purchase of recycled materials and products to be used in the company's processes. This CE practice, which allows companies to reduce the use of raw materials, was adopted by 85 out of 154 respondents $(55.19 \%)$ and its introduction had already been planned by further $37(24.03 \%)$. The purchase of recycled materials and products was more common in the services sector $(65.63 \%)$ than in manufacturing $(50 \%)$ and construction $(40 \%)$; the practice was also positively correlated to the size of the company. Purchased recycled materials and products were used in core activities by 51 companies, in auxiliary processes (such as packaging) by 46 SMEs, and in administrative and general services by 56 companies. Manufacturing enterprises showed a preference for using purchased recycled materials and products in core activities $(56.25 \%)$, whereas companies in construction and services mostly deployed them in administrative and general services ( $50 \%$ and $53.85 \%$, respectively).

Finally, we collected information about the redesign of processes, products, and services in order to produce less waste or prevent it (refuse), according to CE principles. In this regard, 46 respondents out of $143(32.39 \%)$ declared that they had mainly redesigned production processes, while 53 enterprises $(37.32 \%)$ had primarily rethought products and services. In addition, actions were planned in the short term in a further 22 SMEs (15.49\%). In total, $51.35 \%$ of small companies made changes to production processes, whereas $42.16 \%$ of micro-businesses and $66.67 \%$ of medium-sized enterprises redesigned products and services, making the consumers aware of their efforts towards circularity. In manufacturing, 
redesign largely involved production processes (47.76\%); on the other hand, companies operating in the other sectors focused more on the redesign of products and services, as stated by $52.63 \%$ of respondents from construction and $55.36 \%$ from services.

Overall, the results described above are not surprising, as they confirm what had already emerged from a previous study of 254 Italian SMEs conducted by Mura et al. [13]. Their research proved that the CE practices were weakly developed among Italian SMEs, except for separated waste collection, as a consequence of strict national regulation in that field.

\subsection{Benefits and Potential of the $C E$}

We asked the respondents from the companies that had already implemented CE practices to identify one or more benefits they had experienced (Table 11).

Table 11. Benefits experienced from adopting a CE.

\begin{tabular}{|c|c|c|c|c|c|c|c|c|c|c|c|c|c|c|}
\hline \multirow{2}{*}{ Benefits of the CE ${ }^{1}$} & \multicolumn{2}{|c|}{ Total } & \multicolumn{2}{|c|}{ Micro } & \multicolumn{2}{|c|}{ Small } & \multicolumn{2}{|c|}{ Medium } & \multicolumn{2}{|c|}{ Manufacturing } & \multicolumn{2}{|c|}{ Construction } & \multicolumn{2}{|c|}{ Services } \\
\hline & No. & $\%$ & No. & $\%$ & No. & $\%$ & No. & $\%$ & No. & $\%$ & No. & $\%$ & No. & $\%$ \\
\hline $\begin{array}{l}\text { Improved operating efficiency } \\
\text { and cost reduction }\end{array}$ & 63 & $40.65 \%$ & 40 & $36.04 \%$ & 21 & $52.50 \%$ & 2 & $50.00 \%$ & 27 & $38.03 \%$ & 8 & $40.00 \%$ & 28 & $43.75 \%$ \\
\hline Increase in revenues & 22 & $14.19 \%$ & 13 & $11.71 \%$ & 8 & $20.00 \%$ & 1 & $25.00 \%$ & 13 & $18.31 \%$ & 3 & $15.00 \%$ & 6 & $9.38 \%$ \\
\hline Easier access to credit & 3 & $1.94 \%$ & 3 & $2.70 \%$ & 0 & $0.00 \%$ & 0 & $0.00 \%$ & 1 & $1.41 \%$ & 0 & $0.00 \%$ & 2 & $3.13 \%$ \\
\hline Easier access to public funds & 4 & $2.58 \%$ & 3 & $2.70 \%$ & 1 & $2.50 \%$ & 0 & $0.00 \%$ & 3 & $4.23 \%$ & 0 & $0.00 \%$ & 1 & $1.56 \%$ \\
\hline Tax relief & 3 & $1.94 \%$ & 3 & $2.70 \%$ & 0 & $0.00 \%$ & 0 & $0.00 \%$ & 0 & $0.00 \%$ & 0 & $0.00 \%$ & 3 & $4.69 \%$ \\
\hline Development of partnerships & 16 & $10.32 \%$ & 10 & $9.01 \%$ & 6 & $15.00 \%$ & 0 & $0.00 \%$ & 11 & $15.49 \%$ & 0 & $0.00 \%$ & 5 & $7.81 \%$ \\
\hline Other & 17 & $10.97 \%$ & 13 & $11.71 \%$ & 3 & $7.50 \%$ & 1 & $25.00 \%$ & 5 & $7.04 \%$ & 1 & $5.00 \%$ & 11 & $17.19 \%$ \\
\hline None & 55 & $35.48 \%$ & 46 & $41.44 \%$ & 8 & $20.00 \%$ & 1 & $25.00 \%$ & 24 & $33.80 \%$ & 9 & $45.00 \%$ & 22 & $34.38 \%$ \\
\hline
\end{tabular}

${ }^{1}$ One or more options allowed. Percentages are based on the number of responses to the question (total: 155; micro: 111 ; small: 40; medium: 4; manufacturing: 71; construction: 20; services: 64 ).

The survey highlighted that most companies $(64.52 \%)$ had already experienced benefits from implementing CE actions.

Improved operating efficiency, accompanied by cost reduction, was the most common benefit $(40.65 \%)$, with higher frequency in small $(52.50 \%)$ and medium $(50 \%)$ enterprises, as well as within the services sector $(43.75 \%)$. Probably, the internal recovery of materials, the purchase of recycled materials and products for internal use and the redesign of production processes have helped reduce operating costs.

An increase in revenues was underlined by $14.19 \%$ of respondents, with a higher percentage in manufacturing $(18.31 \%)$. As concerns the company size, higher revenues were seen in particular in small- $(20 \%)$ and medium-sized $(25 \%)$ businesses; sales could have grown in medium-sized enterprises because of the redesign of products and services.

Approximately one-tenth of the respondents also reported the development of partnerships (for example, with suppliers and clients) as an actual benefit of the adoption of a $\mathrm{CE}$, especially in manufacturing $(15.49 \%)$ and in small enterprises $(15 \%)$. Conversely, $\mathrm{CE}$ practices did not seem to have contributed to building any partnerships in construction and medium-sized businesses.

In addition, few enterprises experienced financial and fiscal benefits. Only three companies associated the implementation of a CE with easier access to credit, which suggests that the banking and financial system fails to recognize the potential of the $\mathrm{CE}$ to create value and enable businesses to meet stakeholders' economic expectations in the long term.

Similarly, easier access to public funds and tax relief were mentioned by only four and three enterprises, respectively. This suggests the need for a regulatory change to promote public policies that offer greater support to sustainable businesses and improve the assignment of subsidies to the most deserving enterprises.

Finally, a large proportion of enterprises (35.48\%) had already implemented CE practices but had not perceived any benefit from them yet. This unfortunate condition mainly affected the construction sector (45\%) and micro-businesses (41.44\%). 
Through the questionnaire, we also tried to measure the respondents' level of agreement with eight statements about the potential of the CE, as listed in Figure 2. To do so, we used a five-point Likert-type scale, structured as follows: "Strongly disagree"; "Disagree"; "Neither agree nor disagree"; "Agree"; "Strongly agree". Then, we transformed the answers into ordinal data, from 1 ("Strongly disagree") to 5 ("Strongly agree"). Finally, we summarized the respondents' opinions on each statement through a weighted arithmetic mean: this was calculated for all the size- and sector-based categories, as well as distinguishing between businesses that were already adopting a CE and those not yet adopting a CE.

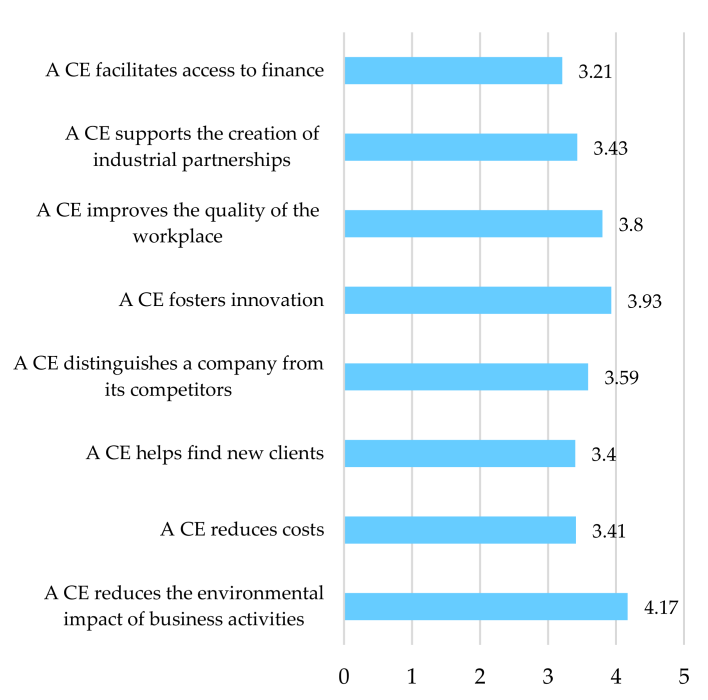

(a) All respondents' opinions on the potential of the $\mathrm{CE}$ (mean value)

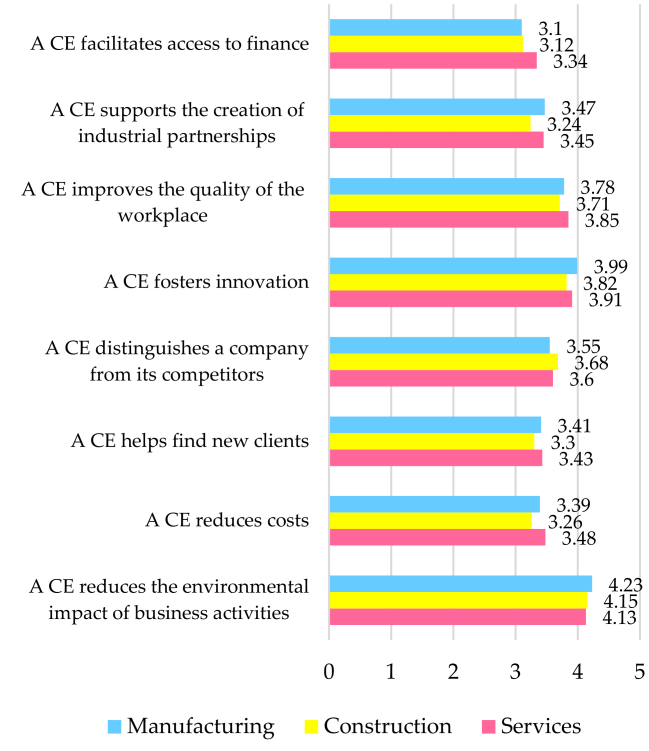

(c) Respondents' opinions by sector (mean value)

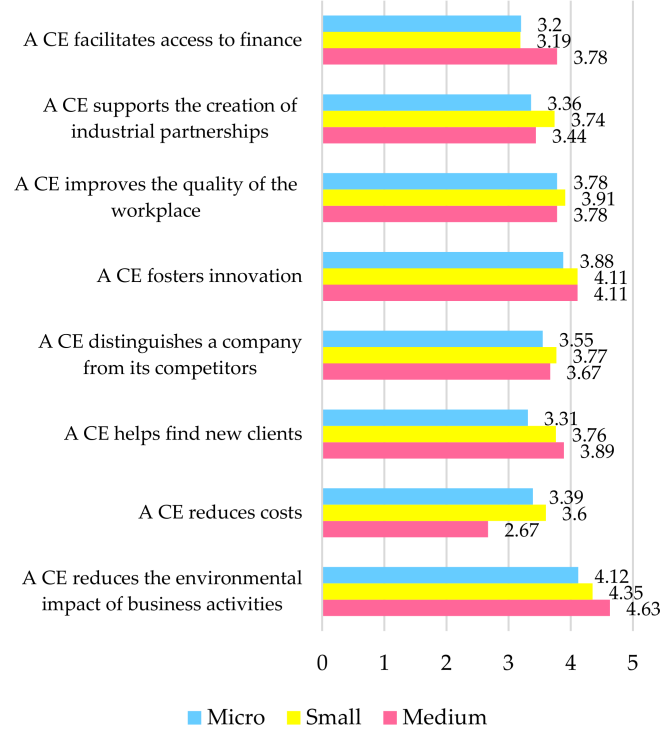

(b) Respondents' opinions by corporate size (mean value)

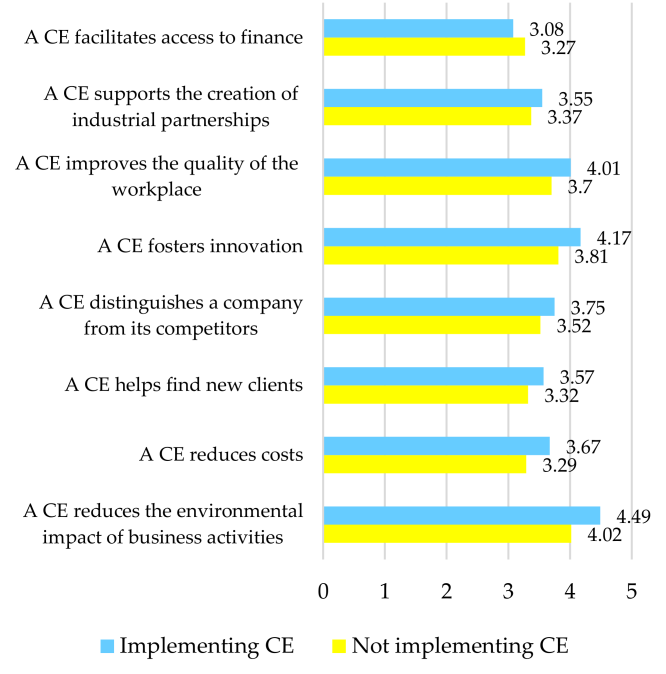

(d) Respondents' opinions by adoption of a CE (mean value)

Figure 2. Respondents' opinions on the potential of the CE (mean value). For each statement, the figure shows the mean value, weighted according to the number of responses obtained from each category of company. Within the same category, the number of responses varies from a statement to another as follows: (a) total: 420-424; (b) micro: 337-341; small: 73-75; medium: 8-9; (c) manufacturing: 163-167; construction: 65-67; services: 190-192; (d) companies implementing CE: 133-136; companies not implementing CE: 286-288. 
The capacity of the CE to reduce the environmental impact of business activities was the only statement that received full agreement among respondents, summarized by a weighted average higher than 4 (4.17). The capacity of the CE to foster innovation (3.93) and to improve the quality of the workplace (3.80) were also largely agreed upon. For all the other statements, the respondents showed a certain difficulty in expressing a clear opinion, as demonstrated by weighted averages between 3.21 and 3.59.

While no significant differences emerged between the sectors analyzed, the size of the business seemed to affect the respondents' opinions. Indeed, medium-sized enterprises expressed a much higher level of agreement than the sample group as a whole on the following four statements: "A CE reduces the environmental impact of business activities"; "A CE helps find new clients"; "A CE fosters innovation"; "A CE facilitates access to finance". However, medium-sized enterprises were also the only category expressing serious doubts (2.67) about whether the CE helped reduce costs.

Finally, the survey enabled us to distinguish between companies that had already adopted CE practices and those with no actual experience in the field. In the first group, opinions about CE were generally much more positive than in the second group. There was only one exception: the capacity of a CE to facilitate access to finance was rated only 3.08 by respondents operating in companies that were already operating in accordance with CE principles, whereas those without direct experience of a CE expressed a slightly higher agreement with the statement (3.27).

\subsection{Barriers to the Deployment of a CE}

The questionnaire helped us understand the barriers to the uptake of a CE in Italy. All the participants involved in the survey were asked to select one or more factors that, in their opinion, might impede or restrict the implementation of CE practices within a business. Overall, the survey enabled us to collect the opinions of 483 respondents (Table 12); more specifically, 139 of them represented enterprises that had already adopted a CE, whereas 344 belonged to organizations in which a CE had never been applied.

Table 12. Factors hindering the uptake of a CE.

\begin{tabular}{|c|c|c|c|c|c|c|c|c|c|c|c|c|c|c|}
\hline \multirow{2}{*}{ Barriers to a $\mathrm{CE}^{1}$} & \multicolumn{2}{|c|}{ Total } & \multicolumn{2}{|c|}{ Micro } & \multicolumn{2}{|c|}{ Small } & \multicolumn{2}{|c|}{ Medium } & \multicolumn{2}{|c|}{ Manufacturing } & \multicolumn{2}{|c|}{ Construction } & \multicolumn{2}{|c|}{ Services } \\
\hline & No. & $\%$ & No. & $\%$ & No. & $\%$ & No. & $\%$ & No. & $\%$ & No. & $\%$ & No. & $\%$ \\
\hline Lack of knowledge and expertise & 156 & $32.30 \%$ & 121 & $31.03 \%$ & 31 & $36.90 \%$ & 4 & $44.44 \%$ & 66 & $35.11 \%$ & 24 & $30.00 \%$ & 66 & $30.70 \%$ \\
\hline $\begin{array}{l}\text { Difficulty making changes to } \\
\text { processes, products and services }\end{array}$ & 78 & $16.15 \%$ & 55 & $14.10 \%$ & 21 & $25.00 \%$ & 2 & $22.22 \%$ & 43 & $22.87 \%$ & 11 & $13.75 \%$ & 24 & $11.16 \%$ \\
\hline Prohibitive investments & 92 & $19.05 \%$ & 76 & $19.49 \%$ & 16 & $19.05 \%$ & 0 & $0.00 \%$ & 41 & $21.81 \%$ & 13 & $16.25 \%$ & 38 & $17.67 \%$ \\
\hline Lack of incentives and support & 118 & $24.43 \%$ & 99 & $25.38 \%$ & 16 & $19.05 \%$ & 3 & $33.33 \%$ & 58 & $30.85 \%$ & 17 & $21.25 \%$ & 43 & $20.00 \%$ \\
\hline Excessive bureaucracy & 91 & $18.84 \%$ & 72 & $18.46 \%$ & 17 & $20.24 \%$ & 2 & $22.22 \%$ & 35 & $18.62 \%$ & 23 & $28.75 \%$ & 33 & $15.35 \%$ \\
\hline Other & 150 & $31.06 \%$ & 129 & $33.08 \%$ & 21 & $25.00 \%$ & 0 & $0.00 \%$ & 51 & $27.13 \%$ & 27 & $33.75 \%$ & 72 & $33.49 \%$ \\
\hline
\end{tabular}

${ }^{1}$ One or more options allowed. Percentages are based on the number of responses to the question (total: 483 micro: 390; small: 84; medium: 9; manufacturing: 188; construction: 80; services: 215).

The major obstacle was identified as the lack of advanced knowledge and specific expertise to adopt CE practices effectively (32.30\%), particularly in small- and mediumsized companies and in the manufacturing sector $(35.11 \%)$.

The difficulty in making changes to production processes, products, and services in order to convert from a linear to a circular business model was also identified by $16.15 \%$ of respondents as a barrier to the uptake of a $\mathrm{CE}$, with higher percentages in medium-sized enterprises (22.22\%) and in manufacturing (22.87\%).

Barriers to CE can be of a financial nature too. In this regard, $19.05 \%$ of respondents mentioned initial or ongoing prohibitive investments, a problem that seemed to affect micro- and small enterprises in all sectors.

Likewise, a lack of incentives and support afflicted one quarter of respondents, with slightly higher frequency among medium-sized businesses (33.33\%) and in the manufacturing sector $(30.85 \%)$.

These results are consistent with those emerged from the already mentioned study involving Romanian SMEs [42]: of the 310 businesses analyzed in that research program, only 
10 had financed their CE transition using non-reimbursable government funds, while only 6 had obtained non-reimbursable grants from the EU or supranational financial institutions.

According to $18.84 \%$ of respondents, excessive bureaucracy was another significant obstacle to the uptake of a CE, especially in construction $(28.75 \%)$. This confirms the results obtained by Mura et al. [13] through the analysis of a sample of Italian SMEs, which rated 4.58 on a 7-point Likert-type scale the bureaucratic difficulty in applying the legislation on sustainability.

\subsection{Use of KPIs to Monitor CE-Related Performance and Transparency towards Stakeholders}

The transition from a linear to a circular business model requires clearly defined targets and related indicators, which enable companies to assess the progress towards the achievement of those objectives [138]. On a micro-level, this entails redesigning the set of KPIs a company adopts in its management control system [139-142] Nevertheless, our findings show that Italian SMEs have thus far failed to give this aspect due importance.

Only 43 respondents out of 424 (10.14\%) declared that they had adopted KPIs concerning the circularity of processes or products, with higher frequency among small $(14.47 \%)$ and medium $(22.22 \%)$ companies, but without significant differences between the three sectors of activity (Table 13). These results are not surprising if we consider the relative costs a company must sustain in order to invest in improvements to its information system, so that it provides a reliable and constantly updated set of non-financial indicators.

Table 13. Adoption of KPIs to drive and monitor the CE.

\begin{tabular}{|c|c|c|c|c|c|c|c|c|c|c|c|c|c|c|}
\hline \multirow{2}{*}{$\begin{array}{c}\text { Adoption } \\
\text { of CE-Related KPIs }\end{array}$} & \multicolumn{2}{|c|}{ Total } & \multicolumn{2}{|c|}{ Micro } & \multicolumn{2}{|c|}{ Small } & \multicolumn{2}{|c|}{ Medium } & \multicolumn{2}{|c|}{ Manufacturing } & \multicolumn{2}{|c|}{ Construction } & \multicolumn{2}{|c|}{ Services } \\
\hline & No. & $\%$ & No. & $\%$ & No. & $\%$ & No. & $\%$ & No. & $\%$ & No. & $\%$ & No. & $\%$ \\
\hline KPIs adopted & 43 & $10.14 \%$ & 30 & $8.85 \%$ & 11 & $14.47 \%$ & 2 & $22.22 \%$ & 15 & $8.93 \%$ & 8 & $11.94 \%$ & 20 & $10.58 \%$ \\
\hline KPIs not adopted & 381 & $89.86 \%$ & 309 & $91.15 \%$ & 65 & $85.53 \%$ & 7 & $77.78 \%$ & 153 & $91.07 \%$ & 59 & $88.06 \%$ & 169 & $89.42 \%$ \\
\hline Total & 424 & $100.00 \%$ & 339 & $100.00 \%$ & 76 & $100.00 \%$ & 9 & $100.00 \%$ & 168 & $100.00 \%$ & 67 & $100.00 \%$ & 189 & $100.00 \%$ \\
\hline
\end{tabular}

More specifically, the survey investigated the usage of a limited number of KPIs regarding recycled materials used in the internal processes of the SMEs surveyed and embedded in the products sold to clients. In addition, the survey considered possible KPIs to monitor employment and job creation in a circular business model. Table 14 highlights the fact that only few businesses had already adopted the CE-related KPIs proposed in the questionnaire: between 11 and 21 SMEs, depending on the specific KPI. The same number of businesses approximately also intended to improve their information system to trace one or more of these indicators.

According to the empirical results presented in Table 15, in approximately two-thirds of the SMEs already adopting CE-related KPIs or of those willing to introduce them, such indicators were, or would be, utilized to establish targets at company level and to measure their achievement. Similarly, the KPIs were, or would be, used to assign targets to staff members and to assess individual performance. In $76.47 \%$ of those same companies, the owner or the board of directors periodically examined the KPIs, a practice that underlines the established importance of the CE as a factor in a company's success and that should underpin its future development. In addition, $71.43 \%$ of SMEs that used or intended to use CE-related KPIs as a management control tool discussed or intended to discuss them with their employees, in order to improve knowledge and understanding of CE targets and results within the organization. Among the sample investigated, small businesses and the companies operating in the manufacturing sector made the largest use of CE-related performance indicators.

In any case, most enterprises had not adopted any CE-related KPIs at the time of the survey. According to Table 16, 245 out of 415 respondents (59.04\%) had met difficulties because of their limited knowledge of KPIs, while $143(34.46 \%)$ were deterred by the costs and complexity of drawing-up CE performance indicators. Finally, 135 respondents (32.53\%) perceived no benefit to implementing CE-related KPIs. This reveals a general 
lack of management control culture within most Italian SMEs, which negatively affects the planning and monitoring of activities that could be crucial in circular business models.

Table 14. List of CE-related KPIs.

\begin{tabular}{|c|c|c|c|c|c|c|c|c|c|c|c|c|c|c|}
\hline \multirow{2}{*}{$\begin{array}{l}\text { Adoption of } \\
\text { KPIs }\end{array}$} & \multicolumn{2}{|c|}{ Total } & \multicolumn{2}{|c|}{ Micro } & \multicolumn{2}{|c|}{ Small } & \multicolumn{2}{|c|}{ Medium } & \multicolumn{2}{|c|}{ Manufacturing } & \multicolumn{2}{|c|}{ Construction } & \multicolumn{2}{|c|}{ Services } \\
\hline & No. & $\%$ & No. & $\%$ & No. & $\%$ & No. & $\%$ & No. & $\%$ & No. & $\%$ & No. & $\%$ \\
\hline \multicolumn{15}{|c|}{ Amount of waste recycled within the company ${ }^{1}$} \\
\hline Already used & 21 & $60.00 \%$ & 15 & $57.69 \%$ & 6 & $66.67 \%$ & 0 & $0.00 \%$ & 7 & $58.33 \%$ & 6 & $85.71 \%$ & 8 & $50.00 \%$ \\
\hline To be introduced & 11 & $31.43 \%$ & 9 & $34.62 \%$ & 2 & $22.22 \%$ & 0 & $0.00 \%$ & 5 & $41.67 \%$ & 0 & $0.00 \%$ & 6 & $37.50 \%$ \\
\hline \multicolumn{15}{|c|}{ Quantity of recycled materials purchased externally to be used in internal processes ${ }^{1}$} \\
\hline Already & 16 & $45.71 \%$ & 10 & $40.00 \%$ & 6 & $66.67 \%$ & 0 & $0.00 \%$ & 6 & $54.55 \%$ & 4 & $57.14 \%$ & 6 & $35.29 \%$ \\
\hline To be introduced & 15 & $42.86 \%$ & 13 & $52.00 \%$ & 2 & $22.22 \%$ & 0 & $0.00 \%$ & 5 & $45.45 \%$ & 2 & $28.57 \%$ & 8 & $47.06 \%$ \\
\hline \multicolumn{15}{|c|}{$\begin{array}{c}\text { Number of industrial, distribution and administrative processes and number of products } \\
\text { that have been redesigned according to CE principles }{ }^{2}\end{array}$} \\
\hline Already & 15 & $41.67 \%$ & 4 & $33.33 \%$ & 3 & $42.86 \%$ & 8 & $47.06 \%$ & 12 & $46.15 \%$ & 2 & $22.22 \%$ & 1 & $100.00 \%$ \\
\hline To be introduced & 16 & $44.44 \%$ & 6 & $50.00 \%$ & 3 & $42.86 \%$ & 7 & $41.18 \%$ & 10 & $38.46 \%$ & 6 & $66.67 \%$ & 0 & $0.00 \%$ \\
\hline \multicolumn{15}{|c|}{$\begin{array}{l}\text { Revenues from sales of products containing recycled materials or parts, } \\
\text { and revenues from direct sales of internally recovered materials }{ }^{2}\end{array}$} \\
\hline Alrec & 13 & $36.11 \%$ & 9 & $34.62 \%$ & 3 & $33.33 \%$ & 1 & $100.00 \%$ & 4 & $33.33 \%$ & 3 & $42.86 \%$ & 6 & $35.29 \%$ \\
\hline To be introduced & 16 & $44.44 \%$ & 12 & $46.15 \%$ & 4 & $44.44 \%$ & 0 & $0.00 \%$ & 7 & $58.33 \%$ & 3 & $42.86 \%$ & 6 & $35.29 \%$ \\
\hline \multicolumn{15}{|c|}{ Quality of products containing recycled materials ${ }^{2}$} \\
\hline Alreac & 16 & $44.44 \%$ & 13 & $50.00 \%$ & 3 & $33.33 \%$ & 0 & $0.00 \%$ & 6 & $50.00 \%$ & 3 & $42.86 \%$ & 7 & $41.18 \%$ \\
\hline To be introduced & 14 & $38.89 \%$ & 10 & $38.46 \%$ & 4 & $44.44 \%$ & 0 & $0.00 \%$ & 5 & $41.67 \%$ & 3 & $42.86 \%$ & 6 & $35.29 \%$ \\
\hline \multicolumn{15}{|c|}{ Number of employees devoted to CE processes ${ }^{2}$} \\
\hline Already & 15 & $41.67 \%$ & 11 & $42.31 \%$ & 3 & $33.33 \%$ & 1 & $100.00 \%$ & 5 & $41.67 \%$ & 4 & $57.14 \%$ & 6 & $35.29 \%$ \\
\hline To be introduced & 11 & $30.56 \%$ & 8 & $30.77 \%$ & 3 & $33.33 \%$ & 0 & $0.00 \%$ & 4 & $33.33 \%$ & 1 & $14.29 \%$ & 6 & $35.29 \%$ \\
\hline \multicolumn{15}{|c|}{ Number of new staff recruited to deal with CE processes ${ }^{2}$} \\
\hline Already used & 11 & $30.56 \%$ & 7 & $26.92 \%$ & 3 & $33.33 \%$ & 1 & $100.00 \%$ & 2 & $16.67 \%$ & 2 & $28.57 \%$ & 7 & $41.18 \%$ \\
\hline To be introduced & 13 & $36.11 \%$ & 10 & $38.46 \%$ & 3 & $33.33 \%$ & 0 & $0.00 \%$ & 8 & $66.67 \%$ & 0 & $0.00 \%$ & 5 & $29.41 \%$ \\
\hline
\end{tabular}

Table 15. Use and analysis of CE-related KPIs.

\begin{tabular}{|c|c|c|c|c|c|c|c|c|c|c|c|c|c|c|}
\hline & \multicolumn{2}{|c|}{ Total } & \multicolumn{2}{|c|}{ Micro } & \multicolumn{2}{|c|}{ Small } & \multicolumn{2}{|c|}{ Medium } & \multicolumn{2}{|c|}{ Manufacturing } & \multicolumn{2}{|c|}{ Construction } & \multicolumn{2}{|c|}{ Services } \\
\hline & No. & $\%$ & No. & $\%$ & No. & $\%$ & No. & $\%$ & No. & $\%$ & No. & $\%$ & No. & $\%$ \\
\hline KPIs are used to establish corporate targets ${ }^{1}$ & 24 & $68.57 \%$ & 18 & $72.00 \%$ & 6 & $66.67 \%$ & 0 & $0.00 \%$ & 8 & $72.73 \%$ & 5 & $71.43 \%$ & 11 & $64.71 \%$ \\
\hline KPIs are used to measure corporate results ${ }^{2}$ & 23 & $67.65 \%$ & 15 & $62.50 \%$ & 7 & $77.78 \%$ & 1 & $100.00 \%$ & 9 & $81.82 \%$ & 3 & $42.86 \%$ & 11 & $68.75 \%$ \\
\hline $\begin{array}{l}\text { KPIs are used to assign individual targets } \\
\text { and assess individual performances }{ }^{2}\end{array}$ & 23 & $67.65 \%$ & 16 & $66.67 \%$ & 7 & $77.78 \%$ & 0 & $0.00 \%$ & 8 & $80.00 \%$ & 4 & $57.14 \%$ & 11 & $64.71 \%$ \\
\hline $\begin{array}{l}\text { KPIs are periodically examined by the } \\
\text { company's owner or board of directors }{ }^{2}\end{array}$ & 26 & $76.47 \%$ & 17 & $70.83 \%$ & 8 & $88.89 \%$ & 1 & $100.00 \%$ & 9 & $90.00 \%$ & 3 & $42.86 \%$ & 14 & $82.35 \%$ \\
\hline $\begin{array}{l}\text { KPIs are illustrated to the employees to } \\
\text { explain the targets that must be pursued } \\
\text { and the results achieved }\end{array}$ & 25 & $71.43 \%$ & 16 & $66.67 \%$ & 8 & $80.00 \%$ & 1 & $100.00 \%$ & 10 & $90.91 \%$ & 4 & $57.14 \%$ & 11 & $64.71 \%$ \\
\hline
\end{tabular}

${ }^{1}$ Percentages are based on the number of responses concerning the specific KPI, as follows: total: 35 ; micro: 25 ; small: 9; medium: 1; manufacturing: 11 ; construction: 7; services: $17 .{ }^{2}$ Percentages are based on the number of responses concerning the specific KPI, as follows: total: 34; micro: 24; small: 9; medium: 1; manufacturing: 11; construction: 7; services: 16 .

Table 16. Factors hindering the use of CE-related KPIs.

\begin{tabular}{|c|c|c|c|c|c|c|c|c|c|c|c|c|c|c|}
\hline \multirow{2}{*}{$\begin{array}{c}\text { Factors Hindering the Use } \\
\text { of CE-Related KPIs }{ }^{1}\end{array}$} & \multicolumn{2}{|c|}{ Total } & \multicolumn{2}{|c|}{ Micro } & \multicolumn{2}{|c|}{ Small } & \multicolumn{2}{|c|}{ Medium } & \multicolumn{2}{|c|}{ Manufacturing } & \multicolumn{2}{|c|}{ Construction } & \multicolumn{2}{|c|}{ Services } \\
\hline & No. & $\%$ & No. & $\%$ & No. & $\%$ & No. & $\%$ & No. & $\%$ & No. & $\%$ & No. & $\%$ \\
\hline e of KPIs & 245 & 59.04 & 194 & $58.43 \%$ & 45 & $60.81 \%$ & 6 & 66.67 & 98 & $60.12 \%$ & 35 & $53.85 \%$ & 112 & 59.89 \\
\hline o & 143 & 34 & 16 & 3 & 25 & 3 & 2 & 22 & 62 & 38. & 26 & 40. & 55 & $29.41 \%$ \\
\hline No benefit perceived & 135 & $32.53 \%$ & 13 & $34.04 \%$ & 18 & $24.32 \%$ & 4 & $44.44 \%$ & 53 & $32.52 \%$ & 22 & $33.85 \%$ & 60 & $32.09 \%$ \\
\hline
\end{tabular}

${ }^{1}$ One or more options allowed. Percentages are based on the number of responses to the question (total: 415 ; micro: 332; small: 74; medium: 9; manufacturing: 163; construction: 65; services: 187).

The concluding part of the questionnaire addressed the external dissemination of corporate data on CE performances. Transparency on CE-related practices, targets and results and other issues of sustainability $[140,141]$ can obviously affect the company's image in a positive way. Therefore, transparency helps strengthen stakeholder trust and 
improve financial, human, and technological resources; it also facilitates the creation and development of relationships throughout the supply chain.

Unfortunately, Table 17 shows that very few of the enterprises we investigated in this research have understood the importance of CE-related accountability. Only 66 businesses of 413 disseminated data on their CE-related practices, targets and results; on the contrary, 347 companies failed to disclose this kind of information externally.

Table 17. Transparency on CE-related practices, targets, and performance.

\begin{tabular}{|c|c|c|c|c|c|c|c|c|c|c|c|c|c|c|}
\hline \multirow{2}{*}{$\begin{array}{c}\text { Dissemination of Data } \\
\text { on CE-Related Practices and } \\
\text { Performance }^{1}\end{array}$} & \multicolumn{2}{|c|}{ Total } & \multicolumn{2}{|c|}{ Micro } & \multicolumn{2}{|c|}{ Small } & \multicolumn{2}{|c|}{ Medium } & \multicolumn{2}{|c|}{ Manufacturing } & \multicolumn{2}{|c|}{ Construction } & \multicolumn{2}{|c|}{ Services } \\
\hline & No. & $\%$ & No. & $\%$ & No. & $\%$ & No. & $\%$ & No. & $\%$ & No. & $\%$ & No. & $\%$ \\
\hline \multicolumn{15}{|c|}{ Transparency on CE } \\
\hline $\begin{array}{c}\text { Companies reporting externally on } \\
\text { the CE }\end{array}$ & 66 & $15.98 \%$ & 44 & $13.33 \%$ & 20 & $27.03 \%$ & 2 & $22.22 \%$ & 31 & $19.02 \%$ & 7 & $10.77 \%$ & 28 & $15.14 \%$ \\
\hline $\begin{array}{c}\text { Companies not reporting externally } \\
\text { on the CE }\end{array}$ & 347 & $84.02 \%$ & 286 & $86.67 \%$ & 54 & $72.97 \%$ & 7 & $77.78 \%$ & 132 & $80.98 \%$ & 58 & $89.23 \%$ & 157 & $84.86 \%$ \\
\hline Total & 413 & $100.00 \%$ & 330 & $100.00 \%$ & 74 & $100.00 \%$ & 9 & $100.00 \%$ & 163 & $100.00 \%$ & 65 & $100.00 \%$ & 185 & $100.00 \%$ \\
\hline \multicolumn{15}{|c|}{ Tools adopted to report about $\mathrm{CE}^{1}$} \\
\hline Sustainability report & 10 & $15.15 \%$ & 5 & $11.36 \%$ & 4 & $20.00 \%$ & 1 & $50.00 \%$ & 5 & $16.13 \%$ & 1 & $14.29 \%$ & 4 & $14.29 \%$ \\
\hline $\begin{array}{l}\text { Environmental statement prepared } \\
\text { in accordance with a standard of } \\
\text { environmental certification }\end{array}$ & 14 & $21.21 \%$ & 8 & $18.18 \%$ & 4 & $20.00 \%$ & 2 & $100.00 \%$ & 4 & $12.90 \%$ & 4 & $57.14 \%$ & 6 & $21.43 \%$ \\
\hline $\begin{array}{l}\text { Management discussion and } \\
\text { analysis accompanying the } \\
\text { annual report }\end{array}$ & 8 & $12.12 \%$ & 6 & $13.64 \%$ & 1 & $5.00 \%$ & 1 & $50.00 \%$ & 3 & $9.68 \%$ & 0 & $0.00 \%$ & 5 & $17.86 \%$ \\
\hline $\begin{array}{l}\text { Reports for third parties (banks, } \\
\text { suppliers, etc.) }\end{array}$ & 17 & $25.76 \%$ & 13 & $29.55 \%$ & 4 & $20.00 \%$ & 0 & $0.00 \%$ & 7 & $22.58 \%$ & 3 & $42.86 \%$ & 7 & $25.00 \%$ \\
\hline Corporate website & 36 & $54.55 \%$ & 23 & $52.27 \%$ & 13 & $65.00 \%$ & 0 & $0.00 \%$ & 19 & $61.29 \%$ & 3 & $42.86 \%$ & 14 & $50.00 \%$ \\
\hline
\end{tabular}

${ }^{1}$ One or more options allowed. Percentages are based on the number of companies reporting externally about CE (total: 66; micro: 44; small: 20; medium: 2; manufacturing: 31; construction: 7; services: 28 ).

Among the 66 businesses providing CE-related information to external stakeholders, a corporate website was the privileged means of communication $(54.55 \%)$, probably due to its high potential to reach the largest audience at low cost $[143,144]$. Some companies used adopted specific non-financial documents to disclose CE-related information, such as a sustainability report (15.15\%) or an environmental statement prepared in accordance with a standard of environmental certification (21.21\%). Finally, CE-related information was published in the management discussion and analysis accompanying the company's annual report $(12.12 \%)$ or in reports for banks, suppliers or other selected third parties $(25.76 \%)$.

\section{Discussion}

This study enabled us to understand the current state of the CE in Italian SMEs. As far as we are aware, our questionnaire received the largest number of responses (623) among the country-based surveys carried out in this field of literature; therefore, our findings can be of valid support to interesting observations. Yet, some caution is needed in generalizing the results, given the still low number of SMEs participating in the survey, especially among those of medium size.

In this section we discuss the results described above. Each of the following subsections focuses on one or more types of results, in the same order we already adopted in Section 4. This also reflects the sequence of the research questions this paper aims at addressing.

\subsection{Need for Information and Training on the $C E$}

The results of our study concerning the awareness and knowledge of the CE in Italian SMEs suggest that a great deal has yet to be done to replace the traditional business models. To be effective, the transition from linear to circular should rely on in-depth knowledge of CE principles, which is unfortunately lacking in half of the sample analyzed, as reported by the respondents. Insufficient knowledge seems to be a widespread problem among SMEs, as other studies have already revealed. For example, Fonseca et al. [115] discovered a general lack of knowledge on legal, fiscal, technical, and organizational aspects of the CE 
among Portuguese businesses. Moreover, Dissanayake and Weerasinghe [145] observed a lack of education of the workforce on corporate sustainability and poor understanding of social and environmental impacts of the company's behavior.

If we refer specifically to the construction sector, which is one of those considered in our study, we note a slightly higher awareness of the CE than in the rest of the sample. This could be due to the need to find ways to manage and reduce the large quantities of discarded materials generated by construction and demolition. Adams et al. [146], who also investigated the construction sector, identified the lack of knowledge on the CE as a barrier to the greater implementation of circular business models. However, this study proved the existence of other more significant factors (such as the failure to consider end-of-life issues) limiting the construction sector's transition to a CE.

According to our research findings, knowledge of the CE mainly derives from business experience, while structured education, training and information programs have played a secondary role until now. Undoubtedly, greater emphasis on the CE is required in different kinds of university courses, from Chemistry and Engineering to Management and Law, as well as in business school programs to ensure solid and extensive knowledge of CE principles and implications. A successful CE transition depends on an adequate education system, which should promote an innovative design education and provide all the necessary skills to develop and manage circular processes and products [145].

In the same way, stronger efforts should be made by trade associations to disseminate information on the $\mathrm{CE}$ and to promote and organize training for professionals in order to improve knowledge and understanding of the CE among entrepreneurs and managers, including those in charge of SMEs. Moreover, the collaborative exchange of valuable experience and sharing of successful CE practices, such as workshops and other major events developed at the industry-level or engaging the supply chain [22] can stimulate micro, small- and medium-sized companies to improve and expand their knowledge of circular business models. This should lead to a comprehensive modernization of the nonfinancial economic system in Italy-in which SMEs accounted for $99.9 \%$ of enterprises, $76.1 \%$ of value added and $64.3 \%$ of employment in 2020 [147], making it more sustainable in the greater interest of all stakeholders.

\subsection{Lack of a Clear Strategic Perspective concerning the CE}

Enterprises that can count on accurate knowledge of the CE are usually more willing to implement circular practices, because they understand the benefits they can obtain, especially in the long term. In such cases, companies recognize the strategic value of the $\mathrm{CE}$ for business success. The literature has underlined that the implementation of a CE is of strategic importance in the mid and long term [148] because it sustains a new business approach that $[149,150]$ :

- Ensures greater resource efficiency,

- Reduces waste,

- Encourages new sources of revenues,

- Enhances corporate image,

- Strengthens employee loyalty,

- Improves investor interest in the company, and

- Attracts new financial resources.

However, the adoption of CE practices can be high risk in the short term, when the increased costs due to the changes made to business processes can deter shareholders from investing [150]. In this sense, risk aversion has been defined as an aptitude barrier to the implementation of a CE [151].

As regards the strategic role of the $\mathrm{CE}$, our empirical results are inconclusive, thus confirming the difference of opinion existing on this point: in fact, half of the respondents agreed on the strategic role of the CE, while the other half disagreed. However, recognition of the strategic importance of the CE tends to grow together with the size of the business; as stated earlier, this could be due to a greater availability of resources, which enables the 
recruitment of more qualified staff who better understand the advantages of implementing a circular business model. It could also be evidence of the strategic nature of the CE in meeting the different expectations of stakeholders-economic, social, and environmentalwhich increase with an increase in company size and require innovative, balanced and sustainable responses in the long term [8,152].

\subsection{Sub-Optimal Exploitation of the Potential of the CE}

A broad application of circular practices is essential for taking full advantage of the CE, a result that isolated initiatives cannot ensure. However, the findings of this study show that the implementation of CE practices by the Italian SMEs that took part in the survey is quite rare, particularly in micro-enterprises. The adoption of circular models increases with the increase in size of the business, thus reflecting the general attitude of Italian SMEs towards environmental sustainability, according to a trend already observed by ISTAT [147] Overall, just $30.21 \%$ of the sample had already undertaken CE-related activities at the time of the investigation: this proportion is much lower than in other countries, such as Romania (where, according to Oncioiu et al. [42], it reached 62.8\%). Italian SMEs are significantly behind the other EU Member States average. As early as 2016, 73.18\% of European SMEs that had already invested in the transition to a more circular model and had implemented at least one CE practice in the previous three years. This was more than double the result we obtained for Italy in 2021. Based on that same survey in 2016, Italy was ranked 19th among the 28 EU countries, with $66.61 \%$ of its SMEs engaged in CE activities [153,154]. Therefore, our study conducted in 2021 appears to show a situation that has worsened in the past five years, although this could be due to the different composition of our sample from that investigated in 2016. However, if the decline is real, it could be caused by the increase in barriers to adopting a CE that our survey also highlighted; these barriers could be discouraging companies to design and implement circular business models, as revealed by the significant proportion of respondents (56.54\% of a total of 566) whose enterprises were not even considering the CE in their future strategies.

Where the transition towards a CE has started, it usually consists in the internal recovery of materials, including packaging and production off-cuts, in the company processes and the purchase of recycled materials and products to be used by the business. In both cases, SMEs can benefit from cost savings, which our results identified as the most common advantage of a circular business model, in line with the findings of other studies [115]. Using recycled goods also protects companies from supply chain-related risks, such as those embedded in procurement processes and connected to the price volatility of raw materials, due to the increasing scarcity of non-renewable natural resources [13,155-157].

More complex actions, such as the redesign of processes, products, and services, are adopted much less frequently, probably because they necessitate technical and engineering skills [158] and the investment of financial resources that SMEs do not currently possess. Similarly, energy production from waste, which requires the installation of specific plants, is even rarer, as already revealed by other studies [159], also focused on SMEs [42].

The overall picture highlights sub-optimal exploitation of the potential of the CE. Italian SMEs adopt CE practices to reduce costs, but they do not specifically associate the $\mathrm{CE}$ with process and product innovation. In general, innovation is widely recognized as one of the most important benefits of the CE to business [156], and our research findings confirm this opinion: indeed, most of the respondents to our questionnaire agreed with the statement that "CE fosters innovation". Nevertheless, Italian SMEs, which are traditionally renowned for their ability to innovate in-house and develop patents [147], still seem unaware of how to turn words into action when it comes to the CE. We discovered that they do not focus on the $\mathrm{CE}$ as a means of product and service diversification, through which they could instead enter new markets, build strategic partnerships downstream, reach different categories of customer and educate consumers to be more sensitive towards environmental issues [160]. 
The lack of strategic perspective can explain why increased revenues have been reported as a positive effect of the CE by only 22 companies of the 155 that, according to our research, have implemented circular practices. Likewise, only 16 SMEs have built partnerships based on a shared circular approach to business.

Most likely, the continued poor knowledge and understanding of the CE among Italian SMEs leads to a short-term and narrow view of its potential. In this regard, our survey proved that most companies are unable to assess whether a CE helps find new customers, supports industrial partnerships and is a distinguishing factor competitively. Given these nebulous ideas about the potential of the $\mathrm{CE}$, it is not surprising that many Italian SMEs have been reluctant to embrace circular business practices.

\subsection{Need to Remove Barriers to the Extensive Implementation of a CE}

Our empirical results confirm the existence of different kinds of barriers to an extensive transition from linear to circular business models, as already stated in earlier investigations [116,161,162].

Some obstacles, which are mostly connected to SMEs' internal organization and functioning, are managerial and technological: the shortage of CE know-how and skills and difficulties in rethinking processes, products, and services with the purpose of closing the loop [158]. In addition, a silo mentality that can cause a certain reluctance by some departments to share information with others constitutes a further barrier to the CE transition $[161,163,164]$.

The lack of the necessary knowledge and expertise could be exacerbated by a mismatch between the demand for and the supply of labor $[155,165,166]$ in a market where large companies attract the most qualified workers, thus depriving SMEs of the expertise required to implement CE measures. This could obviously hinder the innovation of industrial processes and the development of more sustainable products and solutions.

However, even enterprises that employ valuable human resources could face barriers to the widespread adoption of a CE; there could be cultural barriers when consumers are neither aware nor interested in the advantages of using products with a longer life cycle [116] and a lower environmental footprint [167,168].

According to Winans et al. [169], the barriers to the CE transition can be actually due to a lack of stakeholder involvement in a shared vision. Similarly, Ratnasabapathy et al. [170], who investigated the construction industry, identified the lack of communication and coordination among stakeholders as a specific barrier to waste trade.

In such an uncertain context, only few SMEs may be prepared to invest large amounts of capital in promoting a CE, especially if this requires borrowing. The lack of financial resources poses serious challenges for the implementation of the CE in small- and medium companies, as already revealed by many studies $[35,171,172]$. The difficulty for CE-oriented SMEs in accessing finance was also observed [173] with reference to the European context.

In this regard, our study found that financial barriers have been hampering the implementation of circular business models in many Italian SMEs; hardly any of the enterprises participating in the survey have benefited from easier access to credit or public funds as an effect of adopting CE practices. Similarly, respondents expressed little conviction that a CE can help obtain financial resources. In addition, companies adopting CE practices do not benefit from tax concessions and they have to deal with overwhelming bureaucracy, which creates a regulatory barrier aggravating existing difficulties [13,116,174].

In general, we observe the existence of a vicious circle that inhibits the implementation of a CE. In fact, the transition from a linear to a circular model requires the investment of a considerable amount of money. However, as noted by Adams et al. [146], the inclination of companies towards adopting a CE is poorly recognized and appreciated when the enterprise applies for private or public funds to support its transition. This calls for significant actions by national and regional authorities in Italy to support businesses engaged in the transition to a CE. Policy makers should introduce direct measures to promote the CE, such as incentives, tax relief and simplified bureaucracy. All these measures have been 
largely advocated in the existing literature $[13,35,175,176]$, which has particularly underlined the need to connect incentives and tax exemption to higher resource efficiency [177]. In this respect, it is worth mentioning that the lack of incentives and public support was reported by the companies participating in our survey as the second most pressing obstacle to the implementation of a CE. Indirect interventions by public institutions, trade and consumer associations and civil society may also help overcome the skepticism that still exists surrounding the $\mathrm{CE}$ and makes its adoption difficult for Italian SMEs.

Awareness campaigns could be an important instrument for informing consumers about the lower environmental impact of circular solutions involving reusing, repairing, recycling, and refurbishing, with no negative implication on quality. Such campaigns should encourage the consumers who have not yet embraced the green transition $[116,162,178]$ to purchase products and services provided by CE-oriented businesses and to return used products back to the producer [145]. These changes in consumer behavior can stimulate companies to incorporate eco-design principles $[179,180]$ and reward their efforts towards greater sustainability.

In the same manner, more intense dialogue between business associations and the financial sector could make banks and other financial operators more conscious of the fact that CE-oriented SMEs are exposed to fewer risks and open up new market opportunities. Unfortunately, the investment community has often been accused of operating with "shortterm blinkers" [163] looking for rapid return on investment and disregarding projects with wider social and environmental impact but longer financial paybacks [181]. Greater understanding of circular business models should convince the financial institutions that investment in SMEs committed to circularity is a safer option, thus facilitating access to equity capital and credit [182-184].

\subsection{Need to Rethink CE-Related KPIs and External Reporting}

The final objective of our study was understanding the use of CE-related performance indicators in Italian SMEs. Bocken et al. [185] indeed underlined the need to measure the benefits produced by the $\mathrm{CE}$, but also observed the scarcity of such indicators. Haas et al. [186] emphasized the need for reliable KPIs, as the European Commission [187] did in its Action Plan for the CE.

Key performance indicators (KPIs) are helpful tools for driving and measuring a company's progress towards the CE [188]. In fact, KPIs can be used to translate corporate and individual objectives into quantitative targets, the achievement of which can be monitored and assessed more $[189,190]$. Moreover, the proper sharing of CE performance indicators from the board throughout the whole organization creates a common vision based on sustainability principles. This should support the improvement of daily operations and promote strategies to extend product life cycles and reduce waste. Therefore, CE-related KPIs can be integrated with the traditional financial indicators of management control and encourage the monitoring of social and environmental issues as part of effective corporate governance [191-195]. In addition, good CE-related indicators provide relevant information for entrepreneurs and managers in their decision-making [196,197].

Enterprises should also disclose CE performance indicators in corporate reports for the general audience of stakeholders or specific groups [198,199]. By doing so, companies demonstrate their commitment to ensuring a lower environmental impact of their operations and products. In a wider perspective, companies should also report on the efforts undertaken to implement an innovative business model, which enables them to manage new types of risks (such as the difficulty in purchasing raw materials at affordable prices) and to promote green careers for longstanding employees and new recruits.

Despite that the above, we discovered that Italian SMEs make little use of CE-related KPIs to set targets and monitor results, on the one hand, and in corporate reporting, on the other. To date, few companies have consciously implemented CE-related indicators or intend to implement them. Where KPIs have been adopted, they are generally used to establish corporate and individual targets, as well as to monitor and assess performance. In 
addition, such KPIs are periodically analyzed by those in charge of governance decisions, which demonstrates the importance they attribute to CE for long-term success of their businesses. In these companies, CE-related indicators are usually discussed with the employees too: this approach is fundamental for sharing the vision of a business that creates economic and social value while reducing its environmental impact.

However, the majority of SMEs investigated in this study still have a long way to go in terms of CE planning and monitoring. The situation in Italian SMEs is further complicated by the need to improve the whole management control system, which is often not particularly advanced [200-202], as a condition for a broader adoption of CErelated indicators.

Similar considerations apply to external reporting, which is essential for fostering and managing stakeholders' trust. Transparency in relation to CE performance, as well as on CE-related risks, strategies, and policies, requires improvement in most of the enterprises participating in our survey. In this regard, regulatory and standardization bodies can play a crucial role, as they can stimulate SMEs to publish information on their attitude towards the $\mathrm{CE}$, at least by including it in their annual report.

The willingness to adopt sustainable supply chain can further encourage non-financial corporate reporting: the company's need to present itself as a valuable and trustworthy business partner for suppliers of secondary raw materials and buyers of recycled products can positively affect its external communication on CE-related issues.

Finally, the financial sector can encourage transparency on circular business models implemented by enterprises seeking additional funding: greater availability of information helps the assessment of a business's capacity to reduce operational and environmental risks, with important implications for its creditworthiness.

\section{Conclusions}

Circular business models can greatly contribute to building a more sustainable world, in which economic progress and business success are integrated with environmental preservation and social wellbeing in a just and effective manner [203,204].

In Italy, the predominance of SMEs means they bear the weight of the responsibility for achieving sustainability in the country, also through the implementation of CE principles. Thus, this study examined the state of the CE among Italian SMEs, considering both their specific size and sector.

This paper sought to fill a gap in the existing literature, as no previous studies have provided a comprehensive analysis of Italian SMEs with reference to CE-related knowledge and application, recognition of the strategic relevance of the $\mathrm{CE}$, and benefits from and barriers to the transition towards circular business models.

Moreover, this paper contributes to the literature on management control and external reporting. Through a micro-level approach, we investigated the adoption of CE-related KPIs as a tool to support setting targets, monitoring and assessing performance and disseminating information to stakeholders in a responsible and transparent way.

The research, based on an online questionnaire, revealed the existence of cultural, technological, market and financial barriers that have doubtless hampered the spread of a 'close-the-loop' culture among Italian SMEs.

The limited knowledge of CE principles and poor understanding of their potential, combined with difficulties in obtaining public and private funds to finance the transition from linear to circular, are the greatest problems encountered by the companies participating in our study. Overcoming such issues requires serious and rapid action by public institutions, trade and consumer associations and the higher education system in order to develop a friendlier environment for the CE.

Policy makers should provide incentives, such as subsidies, tax relief and support, to encourage the implementation of CE practices in SMEs.

In addition, trade associations play a decisive role in making businesses aware of the benefits of adopting circular business practices, thanks to information campaigns and 
promotion of professional training. Tangible improvement also requires the commitment in particular of academia and advanced education institutes, which should prepare students for work in different kinds of green professions.

Finally, end consumers and citizens should be educated on the environmental, economic and social advantages of purchasing close-the-loop products. This would lead to support for CE-oriented companies that have undertaken a strategic path to sustainability, generating a positive return on their investment.

Some issues remain unsolved: our research did not provide any clear evidence of the link between the $\mathrm{CE}$ and company size; though we expected medium-sized enterprises to be the most committed to a CE, this did not occur systematically. Similarly, we did not identify a sector of activity more devoted to the CE than others.

\subsection{Limitations of This Study}

Admittedly, this study was constrained by some inherent limitations concerning the research method and the composition of respondents.

First, the use of an online questionnaire made it impossible for us to exercise control over respondents and some questions remained unanswered. However, we were aware of this risk since the beginning of this research project and we decided not to force respondents to answer questions they were not interested in, because this could have led to distorted and misleading data.

Second, the sample used is not strictly representative. It is very likely that the sample over-represents forerunners and other SMEs that consider the CE important and so accepted to answer the questionnaire. Moreover, the online distribution of the questionnaire to all CNA members, with no prior selection of specific recipients, led to a disproportionate composition of the sample analyzed. In particular, the participation of medium-sized businesses in this study was very low, which prevented us from generalizing the findings concerning this kind of enterprises.

Third, we did not meet any entrepreneurs or managers directly. Personal interviews and focus groups would have guaranteed us flexibility and adaptability, allowing us to examine more in-depth relevant matters suggested by the respondents, thus developing a better understanding of their concepts of the CE. On the other hand, the path adopted guarantees greater objectivity of the information collected.

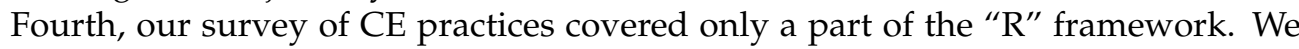
concentrated on activities that can be applied to all sectors; therefore, we did not contemplate practices associated with repair, refurbish, rethink and remanufacture, which we considered more sector-specific.

\subsection{Directions for Future Research}

To conclude, we suggest some future research directions that emerge from our findings and which could help better understand the drivers of uptake of the CE among Italian SMEs. For example, specific analysis of medium-sized enterprises is required. In addition, future research could investigate selected industries (e.g., textile and clothing, food and beverage, electronics, hotels and restaurants, and transport) to map their CE practices according to the " $\mathrm{R}$ " framework. Studies could be undertaken of examples of business excellence in order to establish a benchmark for other companies. Other studies could also focus on the professional profiles required to support the transition from linear to circular business models. Research could explore the impact of public incentives on the uptake of the CE among businesses of different size and sector. Researchers could also examine the extent to which a company's inclination towards the CE effectively affects its creditworthiness. Finally, research is recommended in the field of management control to understand the importance of CE-related KPIs in SME planning and control. 
Author Contributions: Conceptualization, D.M.S., L.B. and T.F.; methodology, L.B.; investigation, L.B. and T.F.; writing-original draft preparation, D.M.S. (Section 6), L.B. (Sections 3-5) and T.F. (Sections 1 and 2); writing-review and editing, L.B. and T.F.; supervision, D.M.S. All authors have read and agreed to the published version of the manuscript.

Funding: This research was financed through ordinary funds from the University of Brescia, Italy.

Institutional Review Board Statement: Not applicable.

Informed Consent Statement: Not applicable.

Data Availability Statement: The data presented in this study are available on request from the corresponding author. The data are not publicly available due to privacy reasons.

Acknowledgments: The authors thank CNA—Confederazione Nazionale dell'Artigianato e della Piccola e Media Impresa (Italy's National Confederation of Craft Trades and Small- and Medium-Sized Enterprises) for the essential support in reviewing and administering the questionnaire survey and in data processing.

Conflicts of Interest: The authors declare no conflict of interest.

\section{References}

1. Geissdoerfer, M.; Savaget, P.; Bocken, N.M.; Hultink, E.J. The Circular Economy-A new sustainability paradigm? J. Clean. Prod. 2017, 143, 757-768. [CrossRef]

2. Stahel, W.R. The circular economy. Nat. News 2016, 531, 435. [CrossRef] [PubMed]

3. Ghisellini, P.; Cialani, C.; Ulgiati, S. A review on circular economy: The expected transition to a balanced interplay of environmental and economic systems. J. Clean. Prod. 2016, 114, 11-32. [CrossRef]

4. Mayer, A.; Haas, W.; Wiedenhofer, D.; Krausmann, F.; Nuss, P.; Blengini, G.A. Measuring progress towards a circular economy: A monitoring framework for economy-wide material loop closing in the EU28. J. Ind. Ecol. 2019, 23, 62-76. [CrossRef] [PubMed]

5. Gregson, N.; Crang, M.; Fuller, S.; Holmes, H. Interrogating the circular economy: The moral economy of resource recovery in the EU. Econ. Soc. 2015, 44, 218-243. [CrossRef]

6. Ma, S.; Wen, Z.; Chen, J.; Wen, Z. Mode of circular economy in China's iron and steel industry: A case study in Wu'an city. J. Clean. Prod. 2014, 64, 505-512. [CrossRef]

7. Teece, D.J. Business models, business strategy and innovation. Long Range Plan. 2010, 43, 172-194. [CrossRef]

8. Salvioni, D.M.; Almici, A. Circular economy and stakeholder engagement strategy. Symph. Emerg. Issues Manag. 2020, 26-44. [CrossRef]

9. Ünal, E.; Urbinati, A.; Chiaroni, D. Managerial practices for designing circular economy business models: The case of an Italian SME in the office supply industry. J. Manuf. Technol. Manag. 2019, 30, 561-588. [CrossRef]

10. Murray, A.; Skene, K.; Haynes, K. The circular economy: An interdisciplinary exploration of the concept and application in a global context. J. Bus. Ethics 2017, 140, 369-380. [CrossRef]

11. Marino, A.; Pariso, P. Comparing European countries' performances in the transition towards the Circular Economy. Sci. Total Environ. 2020, 729, 138142. [CrossRef]

12. Fehrer, J.A.; Wieland, H. A systemic logic for circular business models. J. Bus. Res. 2021, 125, 609-620. [CrossRef]

13. Mura, M.; Longo, M.; Zanni, S. Circular economy in Italian SMEs: A multi-method study. J. Clean. Prod. 2020, $245,118821$. [CrossRef]

14. Aguilar Esteva, L.C.; Kasliwal, A.; Kinzler, M.S.; Kim, H.C.; Keoleian, G.A. Circular economy framework for automobiles: Closing energy and material loops. J. Ind. Ecol. 2021, 25, 877-889. [CrossRef]

15. Hopkinson, P.; Zils, M.; Hawkins, P.; Roper, S. Managing a complex global circular economy business model: Opportunities and challenges. Calif. Manag. Rev. 2018, 60, 71-94. [CrossRef]

16. David, A.; Thangavel, Y.D.; Sankriti, R. Recover, recycle and reuse: An efficient way to reduce the waste. Int. J. Mech. Prod. Eng. Res. Dev. (IJMPERD) 2019, 9, 31-42.

17. Taylor, P. Tire Waste and Recycling. In The 4 Rs: Reduce, Reuse, Recycle, and Recover; Letcher, T., Shulman, V., Amirkhanian, S., Eds.; Elsevier-Academic Press: London, UK, 2021; pp. 71-78.

18. Rodrigues, B.V.; Henriques, P.G. International Scientific Conference PBE2016. In Reduce Reuse Recycle Recover-Need to Rethink Materials in Construction; PBE: Luhacovice, Czech Republic, 2016.

19. Abella, T.A. Follow the Rs: Reduce, replace, reuse, recycle, recover, refuse and reject, rethink. Envirocites eMagazine A Mag. Environ. Cent. Arab Towns 2013, 4, 8-10.

20. Harrold, M.J. Reduce, Reuse, Recycle, Recover: Techniques for Improved Regression Testing; IEEE-International Conference on Software Maintenance: Edmonton, AB, Canada, 2009.

21. Yu, K.H.; Zhang, Y.; Li, D.; Montenegro-Marin, C.E.; Kumar, P.M. Environmental planning based on reduce, reuse, recycle and recover using artificial intelligence. Environ. Impact Assess. Rev. 2021, 86, 106492. [CrossRef] 
22. Salvioni, D.M.; Brondoni, S.M. Ouverture de 'Circular economy \& new business models'. Symph. Emerg. Issues Manag. 2020, 1-9. [CrossRef]

23. Masson-Delmotte, V.; Zhai, P.; Pörtner, H.; Roberts, D.; Skea, J.; Shukla, P.R.; Pirani, A.; Moufouma-Okia, W.; Péan, C.; Pidcock, R. Global warming of 1.5 C. IPCC Spec. Rep. Impacts Glob. Warm. 2018, 1, 630.

24. Martens, P.; McEvoy, D.; Chang, C.T. Climate Change: Responding to a Major Challenge for Sustainable Development. In Sustainability Science; Heinrichs, H., Martens, P., Michelsen, G., Wiek, A., Eds.; Springer: Dordrecht, The Netherlands, 2016; pp. 303-311.

25. Pinkse, J.; Kolk, A. Addressing the Climate Change-Sustainable Development Nexus: The Role of Multistakeholder Partnerships. Bus. Soc. 2021, 51, 176-210. [CrossRef]

26. Princiotta, F.T.; Loughlin, D.H. Global climate change: The quantifiable sustainability challenge. J. Air Waste Manag. Assoc. 2014, 64, 979-994. [CrossRef]

27. Paolillo, A.; Sinval, J.; Silva, S.A.; Scuderi, V.E. The Relationship between Inclusion Climate and Voice Behaviors beyond Social Exchange Obligation: The Role of Psychological Needs Satisfaction. Sustainability 2021, 13, 10252. [CrossRef]

28. Sánchez García, J.L.; Díez Sanz, J.M. Climate change, ethics and sustainability: An innovative approach. J. Innov. Knowl. 2018, 3, 70-75. [CrossRef]

29. Werz, M.; Hoffman, M. Europe's twenty-first century challenge: Climate change, migration and security. Eur. View 2016, 15, 145-154. [CrossRef]

30. Brondoni, S.; Bosetti, L.; Civera, C. Ouverture de 'CSR and multi-stakeholder management'. Symph. Emerg. Issues Manag. 2019, 1-15. [CrossRef]

31. Bosetti, L. Transition towards a low-carbon economy: The contribution of Italian listed utilities. In Proceedings of the 34th EBES Conference, Athens, Greece, 6-8 January 2021.

32. Clark, A.; Dennison, S.; Engström, M. Climate of Cooperation: How the EU Can Help Deliver a Green Grand Bargain-ECFR/421. 2021. Available online: https:/ / ecfr.eu/wp-content/uploads/Climate-of-cooperation-How-the-EU-can-help-deliver-a-greengrand-bargain.pdf (accessed on 20 December 2021).

33. Pineiro-Chousa, J.; Romero-Castro, N.; Vizcaíno-González, M. Inclusions in and exclusions from the S\&P 500 environmental and socially responsible index: A fuzzy-set qualitative comparative analysis. Sustainability 2019, 11, 1211.

34. Salvioni, D.M.; Almici, A. Transitioning toward a circular economy: The impact of stakeholder engagement on sustainability culture. Sustainability 2020, 12, 8641. [CrossRef]

35. Rizos, V.; Behrens, A.; Van der Gaast, W.; Hofman, E.; Ioannou, A.; Kafyeke, T.; Flamos, A.; Rinaldi, R.; Papadelis, S.; HirschnitzGarbers, M. Implementation of circular economy business models by small and medium-sized enterprises (SMEs): Barriers and enablers. Sustainability 2016, 8, 1212. [CrossRef]

36. Atasu, A.; Dumas, C.; Van Wassenhove, L.N. The Circular Business Model. Pick a Strategy that Fits Your Resources and Capabilities. Available online: https://hbr.org/2021/07/the-circular-business-model (accessed on 10 December 2021).

37. Ellen MacArthur Foundation The Circular Economy 100. Available online: https://circular-impacts.eu/library/1351 (accessed on 10 December 2021).

38. Kyoto Club Kyoto Club. Available online: https://www.kyotoclub.org/en/projects-and-initiatives/\#c (accessed on 10 December 2021).

39. CE Club Circular Economy Club. Available online: https:/ / www.circulareconomyclub.com/about/ (accessed on 10 December 2021).

40. European Commission European Circular Economy Stakeholder Platform. Available online: https://circulareconomy.europa.eu/ platform/en (accessed on 10 December 2021).

41. DigiCirc. Available online: https://digicirc.eu/project/ (accessed on 10 December 2021).

42. Oncioiu, I.; Căpuşneanu, S.; Türkes, M.C.; Topor, D.I.; Constantin, D.O.; Marin-Pantelescu, A.; Ștefan Hint, M. The sustainability of Romanian SMEs and their involvement in the circular economy. Sustainability 2018, 10, 2761. [CrossRef]

43. Prieto-Sandoval, V.; Jaca, C.; Santos, J.; Baumgartner, R.J.; Ormazabal, M. Key strategies, resources, and capabilities for implementing circular economy in industrial small and medium enterprises. Corp. Soc. Responsib. Environ. Manag. 2019, 26, 1473-1484. [CrossRef]

44. Ormazabal, M.; Prieto-Sandoval, V.; Puga-Leal, R.; Jaca, C. Circular economy in Spanish SMEs: Challenges and opportunities. J. Clean. Prod. 2018, 185, 157-167. [CrossRef]

45. Piñeiro-Chousa, J.; Vizcaíno-González, M.; Caby, J. Financial development and standardized reporting: A comparison among developed, emerging, and frontier markets. J. Bus. Res. 2019, 101, 797-802. [CrossRef]

46. McNabb, D.E. Research Methods in Public Administration and Nonprofit Management; Routledge: New York, NY, USA, 2017.

47. Korhonen, J.; Honkasalo, A.; Seppälä, J. Circular economy: The concept and its limitations. Ecol. Econ. 2018, 143, 37-46. [CrossRef]

48. Baldassarre, B.; Schepers, M.; Bocken, N.; Cuppen, E.; Korevaar, G.; Calabretta, G. Industrial Symbiosis: Towards a design process for eco-industrial clusters by integrating Circular Economy and Industrial Ecology perspectives. J. Clean. Prod. 2019, 216, 446-460. [CrossRef]

49. Bruel, A.; Kronenberg, J.; Troussier, N.; Guillaume, B. Linking industrial ecology and ecological economics: A theoretical and empirical foundation for the circular economy. J. Ind. Ecol. 2019, 23, 12-21. [CrossRef]

50. Saavedra, Y.M.; Iritani, D.R.; Pavan, A.L.; Ometto, A.R. Theoretical contribution of industrial ecology to circular economy. J. Clean. Prod. 2018, 170, 1514-1522. [CrossRef] 
51. Gallaud, D.; Laperche, B. Circular Economy, Industrial Ecology and Short Supply Chain; John Wiley \& Sons: London, UK; Hoboken, NJ, USA, 2016.

52. Su, B.; Heshmati, A.; Geng, Y.; Yu, X. A review of the circular economy in China: Moving from rhetoric to implementation. J Clean. Prod. 2013, 42, 215-227. [CrossRef]

53. Geng, Y.; Fu, J.; Sarkis, J.; Xue, B. Towards a national circular economy indicator system in China: An evaluation and critical analysis. J. Clean. Prod. 2012, 23, 216-224. [CrossRef]

54. Korhonen, J.; Nuur, C.; Feldmann, A.; Birkie, S.E. Circular economy as an essentially contested concept. J. Clean. Prod. 2018, 175, 544-552. [CrossRef]

55. Ning, D. Cleaner production, eco-industry and circular economy. Res. Environ. Sci. 2001, 14, 1-4.

56. Laso, J.; García-Herrero, I.; Margallo, M.; Vázquez-Rowe, I.; Fullana, P.; Bala, A.; Gazulla, C.; Irabien, Á.; Aldaco, R. Finding an economic and environmental balance in value chains based on circular economy thinking: An eco-efficiency methodology applied to the fish canning industry. Resour. Conserv. Recycl. 2018, 133, 428-437. [CrossRef]

57. Richa, K.; Babbitt, C.W.; Gaustad, G. Eco-efficiency analysis of a lithium-ion battery waste hierarchy inspired by circular economy. J. Ind. Ecol. 2017, 21, 715-730. [CrossRef]

58. Nunes, B.T.; Pollard, S.J.; Burgess, P.J.; Ellis, G.; De los Rios, I.C.; Charnley, F. University contributions to the circular economy: Professing the hidden curriculum. Sustainability 2018, 10, 2719. [CrossRef]

59. Climact. Net zero by 2050: Net Zero by 2050: From Whether to How-Zero Emission Pathways to the Europe We Want. 2018. Available online: https:/ / europeanclimate.org/wp-content/uploads/2019/11/09-18-net-zero-by-2050-from-whether-to-how. pdf (accessed on 20 December 2021).

60. Davis, S.J.; Lewis, N.S.; Shaner, M.; Aggarwal, S.; Arent, D.; Azevedo, I.L.; Benson, S.M.; Bradley, T.; Brouwer, J.; Chiang, Y.-M.; et al. Net-zero emissions energy systems. Science 2018, 360. [CrossRef]

61. Faber, M.; Manstetten, R.; Proops, J. Ecological Economics: Concepts And Methods; Edward Elgar Publishing Ltd.: Cheltenham, $\mathrm{UK}, 1996$.

62. Common, M.; Stagl, S. Ecological Economics: An Introduction; Cambridge University Press: Cambridge, UK, 2005.

63. Gowdy, J.; Erickson, J.D. The approach of ecological economics. Camb. J. Econ. 2005, 29, 207-222. [CrossRef]

64. Ring, I. Evolutionary strategies in environmental policy. Ecol. Econ. 1997, 23, 237-249. [CrossRef]

65. Costanza, R.; Cumberland, J.H.; Daly, H.; Goodland, R.; Norgaard, R.B. An Introduction to Ecological Economics; CRC Press-St. Lucie Press: Boca Raton, FL, USA, 1997.

66. Rodriguez-Anton, J.M.; Rubio-Andrada, L.; Celemín-Pedroche, M.S.; Alonso-Almeida, M. Analysis of the relations between circular economy and sustainable development goals. Int. J. Sustain. Dev. World Ecol. 2019, 26, 708-720. [CrossRef]

67. Liu, Q.; Li, H.; Zuo, X.; Zhang, F.; Wang, L. A survey and analysis on public awareness and performance for promoting circular economy in China: A case study from Tianjin. J. Clean. Prod. 2009, 17, 265-270. Available online: https://doi.org/10.1016/j jclepro.2008.06.003 (accessed on 3 November 2021). [CrossRef]

68. Ellen MacArthur Foundation. What We Do. Available online: https://ellenmacarthurfoundation.org/about-us/what-we-do (accessed on 3 November 2021).

69. Wagner, H.M.; Whitin, T.M. Dynamic version of the economic lot size model. Manag. Sci. 1958, 5, 89-96. [CrossRef]

70. Coomer, J.C. Quest for a Sustainable Society; Elsevier: New York, NY, USA, 1981.

71. Min, Y. The German Circular Economy Act. Environ. Guid. News 1997, 3, 40-43.

72. Leontief, W. The economy as a circular flow. Struct. Chang. Econ. Dyn. 1991, 2, 181-212. [CrossRef]

73. Johnson, J.C.; Wood, D.F. (Eds.) Contemporary Logistics; Macmillan: New York, NY, USA, 1990.

74. Garza-Reyes, J.A.; Salomé Valls, A.; Peter Nadeem, S.; Anosike, A.; Kumar, V. A circularity measurement toolkit for manufacturing SMEs. Int. J. Prod. Res. 2019, 57, 7319-7343. [CrossRef]

75. Dey, P.K.; Malesios, C.; De, D.; Budhwar, P.; Chowdhury, S.; Cheffi, W. Circular economy to enhance sustainability of small and medium-sized enterprises. Bus. Strategy Environ. 2020, 29, 2145-2169. [CrossRef]

76. Andersen, M.S. An introductory note on the environmental economics of the circular economy. Sustain. Sci. 2007, 2, 133-140. [CrossRef]

77. Lieder, M.; Rashid, A. Towards circular economy implementation: A comprehensive review in context of manufacturing industry. J. Clean. Prod. 2016, 115, 36-51. [CrossRef]

78. Kirchherr, J.; Reike, D.; Hekkert, M. Conceptualizing the circular economy: An analysis of 114 definitions. Resour. Conserv. Recycl. 2017, 127, 221-232. [CrossRef]

79. Vanner, R.; Bicket, M.; Withana, S.; ten Brink, P.; Razzini, P.; van Dijl, E.; Watkins, E.; Hestin, M.; Tan, A.; Guilcher, S.; et al. Scoping Study to Identify Potential Circular Economy Actions, Priority Sectors, Material Flows \& Value Chains (DG Environment's Framework Contract for Economic Analysis ENV.F.1/FRA/2010/ 0044 No. Final Report). Policy Studies Institute (PSI), Institute for European Environmental Policy (IEEP), BIO and Ecologic Institute. 2014. Available online: https://op.europa.eu/en/publicationdetail/- / publication/0619e465-581c-41dc-9807-2bb394f6bd07/language-en (accessed on 3 November 2021).

80. European Parliament. Circular Economy: Definition, Importance and Benefits. 2015. Available online: https://www.europarl europa.eu/news/en/headlines/economy/20151201STO05603/circular-econo-my-definition-importance-and-benefits (accessed on 3 November 2021). 
81. Ellen MacArthur Foundation. Growth Within: A Circular Economy Vision for a Competitive Europe. 2015. Available online: https:/ / www.mckinsey.de/files/growth_within_report_circular_economy_in_europe.pdf (accessed on 3 November 2021).

82. OECD. Forum 2016 Issues: International Collaboration. Available online: https://www.oecd.org/forum/issues / forum-2016 -issues-international-collaboration.htm (accessed on 3 November 2021).

83. Sauvé, S.; Bernard, S.; Sloan, P. Environmental sciences, sustainable development and circular economy: Alternative concepts for trans-disciplinary research. Environ. Dev. 2016, 17, 48-56. [CrossRef]

84. Circular Academy. Circular Economy: Some Definitions. 2017. Available online: http://www.circular.academy/circulareconomy-some-definitions / (accessed on 3 November 2021).

85. Lewandowski, M. Designing the business models for circular economy-Towards the conceptual framework. Sustainability 2016, 8, 43. [CrossRef]

86. Roos Lindgreen, E.; Salomone, R.; Reyes, T. A critical review of academic approaches, methods and tools to assess circular economy at the micro level. Sustainability 2020, 12, 4973. [CrossRef]

87. Elia, V.; Gnoni, M.G.; Tornese, F. Measuring circular economy strategies through index methods: A critical analysis. J. Clean. Prod. 2017, 142, 2741-2751. [CrossRef]

88. Kristensen, H.S.; Mosgaard, M.A. A review of micro level indicators for a circular economy-moving away from the three dimensions of sustainability? J. Clean. Prod. 2020, 243, 118531. [CrossRef]

89. Franco, M.A. Circular economy at the micro level: A dynamic view of incumbents' struggles and challenges in the textile industry. I. Clean. Prod. 2017, 168, 833-845. [CrossRef]

90. Saidani, M.; Yannou, B.; Leroy, Y.; Cluzel, F.; Kendall, A. A taxonomy of circular economy indicators. J. Clean. Prod. 2019, 207, 542-559. [CrossRef]

91. Merli, R.; Preziosi, M.; Acampora, A. How do scholars approach the circular economy? A systematic literature review. J. Clean. Prod. 2018, 178, 703-722. [CrossRef]

92. Mat'ová, H.; Kaputa, V.; Triznová, M. Responsible Consumer in the context of Circular Economy. Digitalisation and circular economy: Forestry and forestry based industry implications. Available online: http://www.woodema.org/proceedings/ WoodEMA_2019_Proceedings.pdf (accessed on 3 November 2021).

93. King, A.M.; Burgess, S.C.; Ijomah, W.; McMahon, C.A. Reducing waste: Repair, recondition, remanufacture or recycle? Sustain. Dev. 2006, 14, 257-267. [CrossRef]

94. Brennan, G.; Tennant, M.; Blomsma, F. Business and Production Solutions: Closing Loops and the Circular Economy. In Sustainability. Key Issues, 1st ed.; Kopnina, H., Shoreman-Ouimet, E., Eds.; Routledge: Abingdon, UK; New York, NY, USA, 2015; pp. 219-240.

95. Europen Parliament. Directive 2008/98/EC of the European Parliament and of the Council of 19 November 2008 on waste and repealing certain Directives. Off. J. Eur. Union L 2008, L312, 3-30.

96. Sihvonen, S.; Ritola, T. Conceptualizing ReX for aggregating end-of-life strategies in product development. Procedia Cirp. 2015, 29, 639-644. [CrossRef]

97. Van Buren, N.; Demmers, M.; Van der Heijden, R.; Witlox, F. Towards a circular economy: The role of Dutch logistics industries and governments. Sustainability 2016, 8, 647. [CrossRef]

98. Ekins, P.; Domenech, T.; Drummond, P.; Bleischwitz, R.; Hughes, N.; Lotti, L. The Circular Economy: What, Why, How and Where. Available online: https:/ / www.oecd.org/cfe/regionaldevelopment/Ekins-2019-Circular-Economy-What-Why-How-Where.pdf (accessed on 20 December 2021).

99. Potting, J.; Hekkert, M.P.; Worrell, E.; Hanemaaijer, A. Circular Economy: Measuring Innovation in The Product Chain; PBL Netherlands Environmental Assessment Agency: The Hague, The Netherlands, 2017.

100. Europen Commission. First Circular Economy Action Plan. 2015. Available online: https:/ / ec.europa.eu/environment/topics/ circular-economy / first-circular-economy-action-plan_it (accessed on 3 November 2021).

101. European Commission. A new Circular Economy Action Plan. 2020. Available online: https://eur-lex.europa.eu/legal-content/ EN/TXT/?qid=1583933814386\&uri=COM:2020:98:FIN (accessed on 3 November 2021).

102. European Commission. Internal Market, Industry, Entrepreneurship and SMEs. Available online: https://ec.europa.eu/growth/ smes/sme-definition_en (accessed on 3 November 2021).

103. Rubio-Mozos, E.; García-Muiña, F.E.; Fuentes-Moraleda, L. Rethinking 21st-century businesses: An approach to fourth sector SMEs in their transition to a sustainable model committed to SDGs. Sustainability 2019, 11, 5569. [CrossRef]

104. Moeuf, A.; Pellerin, R.; Lamouri, S.; Tamayo-Giraldo, S.; Barbaray, R. The industrial management of SMEs in the era of Industry 4.0. Int. J. Prod. Res. 2018, 56, 1118-1136. [CrossRef]

105. Masroor, N.; Asim, M. SMEs in the contemporary era of global competition. Procedia Comput. Sci. 2019, 158, 632-641. [CrossRef]

106. Ghența, M.; Matei, A. SMEs and the circular economy: From policy to difficulties encountered during implementation. Amfiteatru Econ. 2018, 20, 294-309. [CrossRef]

107. Negri, M.; Neri, A.; Cagno, E.; Monfardini, G. Circular Economy Performance Measurement in Manufacturing Firms: A Systematic Literature Review with Insights for Small and Medium Enterprises and New Adopters. Sustainability 2021, $13,9049$. [CrossRef]

108. Feil, A.A.; de Quevedo, D.M.; Schreiber, D. An analysis of the sustainability index of micro-and small-sized furniture industries. Clean Technol. Environ. Policy 2017, 19, 1883-1896. [CrossRef] 
109. Mitchell, S.; O'Dowd, P.; Dimache, A. Manufacturing SMEs doing it for themselves: Developing, testing and piloting an online sustainability and eco-innovation toolkit for SMEs. Int. J. Sustain. Eng. 2020, 13, 159-170. [CrossRef]

110. Bajdor, P.; Pawełoszek, I.; Fidlerova, H. Analysis and assessment of sustainable entrepreneurship practices in Polish small and medium enterprises. Sustainability 2021, 13, 3595. [CrossRef]

111. Matejun, M. The role of flexibility in building the competitiveness of small and medium enterprises. Management 2014, 18, 154-168. [CrossRef]

112. Demirel, P.; Damisman, G.O. Eco-innovation and firm growth in the cricular economy: Evidence form European Small and Medium sized enterprises. Bus. Strategy Environ. 2019, 28, 1068-1618. [CrossRef]

113. Principato, L.; Ruini, L.; Guidi, M.; Secondi, L. Adopting the circular economy approach on food loss and waste: The case of Italian pasta production. Resour. Conserv. Recycl. 2019, 144, 82-89. [CrossRef]

114. Walker, A.M.; Opferkuch, K.; Roos Lindgreen, E.; Simboli, A.; Vermeulen, W.J.V.; Raggi, A. Assessing the social sustainability of circular economy practices: Industry perspectives from Italy and the Netherlands. Sustain. Prod. Consum. 2021, 27, 831-844. [CrossRef]

115. Fonseca, L.M.; Domingues, J.P.; Pereira, M.T.; Martins, F.F.; Zimon, D. Assessment of circular economy within Portuguese organizations. Sustainability 2018, 10, 2521. [CrossRef]

116. Kirchherr, J.; Piscicelli, L.; Bour, R.; Kostense-Smit, E.; Muller, J.; Huibrechtse-Truijens, A.; Hekkert, M. Barriers to the Circular Economy: Evidence from the European Union (EU). Ecol. Econ. 2018, 150, 264-272. [CrossRef]

117. Rincón-Moreno, J.; Ormazábal, M.; Álvarez, M.J.; Jaca, C. Advancing circular economy performance indicators and their application in Spanish companies. J. Clean. Prod. 2021, 279, 123605. [CrossRef]

118. Ferasso, M.; Beliaeva, T.; Kraus, S.; Clauss, T.; Ribeiro-Soriano, D. Circular economy business models: The state of research and avenues ahead. Bus. Strategy Environ. 2020, 29, 3006-3024. [CrossRef]

119. Hair, J.F.; Page, M.; Brunsveld, N. Essentials of Business Research Methods; Routledge: New York, NY, USA; Abingdon, UK, 2019.

120. Welman, C.; Kruger, F. Research Methodology for The Business \& Administrative Sciences; Oxford University Press: Oxford, UK, 2001

121. Hoonakker, P.; Carayon, P. Questionnaire survey nonresponse: A comparison of postal mail and internet surveys. Int. J. Hum.-Comput. Interact. 2009, 25, 348-373. [CrossRef]

122. Michalos, A.C. Encyclopedia of Quality of Life and Well-Being Research; Springer: Dordrecht, The Netherlands, 2014.

123. Fan, W.; Yan, Z. Factors affecting response rates of the web survey: A systematic review. Comput. Hum. Behav. 2010, 26, 132-139. [CrossRef]

124. Keusch, F. Why do people participate in Web surveys? Applying survey participation theory to Internet survey data collection. Manag. Rev. Q. 2015, 65, 183-216. [CrossRef]

125. Zhou, R.; Wang, X.; Zhang, L.; Guo, H. Who tends to answer open-ended questions in an e-service survey? The contribution of closed-ended answers. Behav. Inf. Technol. 2017, 36, 1274-1284. [CrossRef]

126. Lakatos, I.; Feyerabend, P. For and Against Method; University of Chicago Press: Chicago, IL, USA, 2010.

127. Holzer, D.; Rauter, R.; Fleiß, E.; Stern, T. Mind the gap: Towards a systematic circular economy encouragement of small and medium-sized companies. J. Clean. Prod. 2021, 298, 126696. [CrossRef]

128. Cameli, M.; Novo, G.; Tusa, M.; Mandoli, G.E.; Corrado, G.; Benedetto, F.; Antonini-Canterin, F.; Citro, R. How to Write a Research Protocol: Tips and Tricks. J. Cardiovasc. Echogr. 2018, 28, 151-153.

129. Fathalla, M.F. A Practical Guide for Health Researchers; WHO Regional Publications, Eastern Mediterranean Series 30; World Health Organization; Regional Office for the Eastern Mediterranean: Cairo, Egypt, 2004; pp. 1-235.

130. Rout, C.C.; Aldous, C. How to write a research protocol. S. Afr. J. Anaesth. Analg. 2016, 22, 101-107. [CrossRef]

131. Taherdoost, H. Validity and reliability of the research instrument. How to test the validation of a questionnaire/survey in a research. Int. J. Acad. Res. Manag. 2016, 5, 28-36. [CrossRef]

132. Deniz, M.S.; Alsaffar, A.A. Assessing the validity and reliability of a questionnaire on dietary fibre-related knowledge in a Turkish student population. J. Health Popul. Nutr. 2013, 31, 497-503. [CrossRef]

133. Trochim, W.M.K. The Research Methods Knowledge Base. Available online: https://conjointly.com/kb/ (accessed on 13 December 2021).

134. Oluwatayo, J. Validity and reliability issues in educational research. J. Educ. Soc. Res. 2012, 2, 391-400.

135. Boudreau, M.; Gefen, D.; Straub, D. Validation in Information Systems research: A state-of-the-art assessment. MIS Q. 2001, 25, 1-16. [CrossRef]

136. Wickström, G.; Bendix, T. The "Hawthorne effect"-What did the original Hawthorne studies actually show? Scand. J. Work Environ. Health 2000, 26, 363-367. Available online: https://www.jstor.org/stable/40967074 (accessed on 10 December 2021). [CrossRef]

137. ISTAT. Permanent Census. 2019. Available online: https://www.istat.it/it/censimenti/imprese (accessed on 3 November 2021).

138. Rincón-Moreno, J.; Ormazábal, M.; Jaca, C. Stakeholder Perspectives in Transitioning to a Local Circular Economy: A Case Study in Spain. Circ. Econ. Sustain. 2021, 1-19. [CrossRef]

139. Svensson, N.; Funck, E.K. Management control in circular economy. Exploring and theorizing the adaptation of management control to circular business models. J. Clean. Prod. 2019, 233, 390-398. [CrossRef]

140. EASAC. Indicators for a Circular Economy. EASAC Policy Report 30. 2016. Available online: https://easac.eu/fileadmin/PDF_s/ reports_statements/Circular_Economy/EASAC_Indicators_web_complete.pdf (accessed on 10 December 2021). 
141. Davila, T. An exploratory study on the emergence of management control systems: Formalizing human resources in small growing firms. Account. Organ. Soc. 2005, 30, 223-248. [CrossRef]

142. Iacovidou, E.; Velis, C.A.; Purnell, P.; Zwirner, O.; Brown, A.; Hahladakis, J.; Millward-Hopkins, J.; Williams, P.T. Metrics for optimising the multi-dimensional value of resources recovered from waste in a circular economy: A critical review. J. Clean. Prod. 2017, 166, 910-938. [CrossRef]

143. Elsayed, A.; Elbeltagi, I.; El-Masry, A.A. Online disclosure: An analysis of Egyptian listed companies. Corp. Ownersh. Control 2010, 8, 552-568. [CrossRef]

144. Oyelere, P.B.; Kuruppu, N.T. Corporate characteristics of listed companies engaging in web-based financial reporting in emerging economies. Corp. Ownersh. Control 2016, 13, 66-80. [CrossRef]

145. Dissanayake, D.; Weerasinghe, D. Towards Circular Economy in Fashion: Review of Strategies, Barriers and Enablers. Circ. Econ. Sust. 2021. [CrossRef]

146. Adams, K.T.; Osmani, M.; Thorpe, T.; Thornback, J. Circular economy in construction: Current awareness, challenges and enablers Proc. Inst. Civil. Eng.-Waste Resour. Manag. 2017, 170, 15-24. [CrossRef]

147. European Commission. Italy-SME Fact Sheet 2021. Available online: https://ec.europa.eu/docsroom/documents/46080 (accessed on 3 November 2021).

148. Hopkinson, P.; De Angelis, R.; Zils, M. Systemic building blocks for creating and capturing value from circular economy, Resources. Conserv. Recycl. 2020, 155, 104672. [CrossRef]

149. Barros, M.V.; Salvador, R.; do Prado, G.F.; de Francisco, A.C.; Piekarski, C.M. Circular economy as a driver to sustainable businesses. Clean. Environ. Syst. 2021, 2, 100006. [CrossRef]

150. Fortunati, S.; Martiniello, L.; Morea, D. The Strategic Role of the Corporate Social Responsibility and Circular Economy in the Cosmetic Industry. Sustainability 2020, 12, 5120. [CrossRef]

151. Ritzén, S.; Sandström, G.Ö. Barriers to the Circular Economy-integration of perspectives and domains. Procedia Cirp. 2017, 64, 7-12. [CrossRef]

152. Gennari, F.; Cassano, R. Circular economy and strategic risk. Symph. Emerg. Issues Manag. 2020, 136-148. [CrossRef]

153. European Commission: Flash Eurobarometer 441: European SMEs and the Circular Economy. Available online: https://data. europa.eu/data/datasets/s2110_441_eng?locale=en (accessed on 15 December 2021).

154. Bassi, F.; Dias, J.G. The use of circular economy practices in SMEs across the EU. Resour. Conserv. Recycl. 2019, 146, 523-533. [CrossRef]

155. European Commission. Impacts of Circular Economy Policies on the Labour Market. Final Report and Annexes. 2018. Available online: https:/ / op.europa.eu/it/publication-detail/- / publication/fc373862-704d-11e8-9483-01aa75ed71a1 (accessed on 3 November 2021).

156. KPMG. Let's Help SMEs to Go Circular. Part of the Project: Boosting the Circular Economy Amongst Smes In Europe—A Project of the European Commission-DG Environment. 2018. Available online: https://ec.europa.eu/environment/sme/pdf/Training\%20 materials_English.pdf (accessed on 3 November 2021).

157. Govindan, K.; Hasanagic, M. A systematic review on drivers, barriers, and practices towards circular economy: A supply chain perspective. Int. J. Prod. Res. 2018, 56, 278-311. [CrossRef]

158. De Jesus, A.; Mendonça, S. Lost in transition? Drivers and barriers in the ecoinnovation road to the circular economy. Ecol. Econ. 2018, 145, 75-89. [CrossRef]

159. UNDESA-United Nations Department of Economic and Social Affairs 2011. World Economic and Social Survey 2011-The Great Green Technological Transformation. Available online: https://www.un.org/en/development/desa/policy/wess/wess_ current/2011wess.pdf (accessed on 15 December 2021).

160. Nikolaou, I.E.; Tasopoulou, K.; Tsagarakis, K. A typology of green entrepreneurs based on institutional and resource-based views. J. Entrep. 2018, 27, 111-132. [CrossRef]

161. Pheifer, A.G. Barriers and Enablers to Circular Business Models. 2017. Available online: https://www.circulairondernemen.nl/ uploads /4f4995c266e00bee8fdb8fb34fbc5c15 (accessed on 3 November 2021).

162. Mont, O.; Plepys, A.; Whalen, K.; Nußholz, J.L. Business Model Innovation for a Circular Economy: Drivers and Barriers for the Swedish Industry-The voice of REES companies. Institute for Industrial Environmental Economics, Lund University. 2017. Available online: https://lucris.lub.lu.se/ws/portalfiles/portal/33914256/MISTRA_REES_Drivers_and_Barriers_Lund.pdf (accessed on 3 November 2021).

163. Hart, J.; Adams, K.; Giesekam, J.; Densley Tingley, D.; Pomponi, F. Barriers and drivers in a circular economy: The case of the built environment. Procedia CIRP 2019, 80, 619-624. [CrossRef]

164. Liu, Y.; Bai, Y. An exploration of firms' awareness and behavior of developing circular economy: An empirical research in China. Resour. Conserv. Recycl. 2014, 87, 145-152. [CrossRef]

165. Mitchell, P.; Morgan, J. Employment and the Circular Economy. Job Creation in a More Resource Efficient Britain; Green Alliance: London, UK; WRAP: Banbury, UK, 2015.

166. OECD. Employment Implications of Green Growth: Linking jobs, growth, and green policies. OECD Report for the G7 Environment Ministers. 2017. Available online: https://www.oecd.org/environment/Employment-Implications-of-GreenGrowth-OECD-Report-G7-Environment-Ministers.pdf (accessed on 3 November 2021). 
167. Finkbeiner, M. Product environmental footprint breakthrough or breakdown for policy implementation of life cycle assessment? Int. J. Life Cycle Assess. 2014, 19, 266-271. [CrossRef]

168. He, B.; Xiao, J.; Deng, Z. Product design evaluation for product environmental footprint. J. Clean. Prod. 2018, 172, 3066-3080. [CrossRef]

169. Winans, K.; Kendall, A.; Deng, H. The history and current applications of the circular economy concept. Renew. Sustain. Energy Rev. 2017, 68, 825-833. [CrossRef]

170. Ratnasabapathy, S.; Alashwal, A.; Perera, S. Exploring the barriers for implementing waste trading practices in the construction industry in Australia. Built Environ. Proj. Asset Manag. 2021, 11, 559-576. [CrossRef]

171. Caldera, H.T.S.; Desha, C.; Dawes, L. Evaluating the enablers and barriers for successful implementation of sustainable business practice in 'lean' SMEs. J. Clean. Prod. 2019, 218, 575-590. [CrossRef]

172. D'Amato, D.; Veijonaho, S.; Toppinen, A. Towards sustainability? Forest-basedcircular bioeconomy business models in Finnish SMEs. For. Policy Econ. 2018, 110, 101848. [CrossRef]

173. Garces-Ayerbe, C.; Rivera-Torres, P.; Suarez-Perales, I.; La Hiz, D.I.L.D. Is it possible to change from a linear to a circular economy? An overview of opportunities and barriers for European small and medium-sized enterprise companies. Int. J. Environ. Res. Publ. Health 2019, 16, 851. [CrossRef]

174. Dieckmann, E.; Sheldrick, L.; Tennant, M.; Myers, R.; Cheeseman, C. Analysis of barriers to transitioning from a linear to a circular economy for end of life materials: A case study for waste feathers. Sustainability 2020, 12, 1725. [CrossRef]

175. Briguglio, M.; Llorente-González, L.J.; Meilak, C.; Pereira, Á.; Spiteri, J.; Vence, X. Born or Grown: Enablers and Barriers to Circular Business in Europe. Sustainability 2021, 13, 13670. [CrossRef]

176. Xue, B.; Chen, X.-P.; Geng, Y.; Guo, X.-J.; Lu, C.-P.; Zhang, Z.-L.; Lu, C.-Y. Survey of officials' awareness on circular economy development in China: Based on municipal and county level, Resources. Conserv. Recycl. 2010, 54, 1296-1302. [CrossRef]

177. van Keulen, M.; Kirchherr, J. The implementation of the Circular Economy: Barriers and enablers in the coffee value chain. J. Clean. Prod. 2021, 281, 125033. [CrossRef]

178. Singh, P.; Giacosa, E. Cognitive biases of consumers as barriers in transition towards circular economy. Manag. Decis. 2019, 57, 921-936. [CrossRef]

179. Bovea, M.D.; Pérez-Belis, V. Identifying design guidelines to meet the circular economy principles: A case study on electric and electronic equipment. J. Environ. Manag. 2018, 228, 483-494. [CrossRef]

180. Corsini, F.; Gusmerotti, N.M.; Frey, M. Consumer's Circular Behaviors in Relation to the Purchase, Extension of Life, and End of Life Management of Electrical and Electronic Products: A Review. Sustainability 2020, 12, 10443. [CrossRef]

181. Carra, G.; Magdani, N. Circular Business Models for the Built Environment, Arup, BAM, CE100. 2017. Available online: https:// circulareconomy.europa.eu/platform/sites/default/files/knowledge_-_circular_business-models-for_the_environment.pdf (accessed on 10 December 2021).

182. European Investment Bank. Access-to-finance conditions for Projects supporting Circular Economy. Prepared for DG Research and Innovation, European Commission by InnovFin Advisory. 2015. Available online: https://www.eib.org/attachments/pj/ access_to_finance_study_on_circular_economy_en.pdf (accessed on 20 December 2021).

183. Mishra, J.L.; Hopkinson, P.; Tidridge, G. Value creation from circular economy-led closed loop supply chains: A case study of fast-moving consumer goods. Prod. Plan. Control 2018, 29, 509-521. [CrossRef]

184. Van Eijk, F. Barriers and Drivers Towards a Circular Economy-Literature Review. Acceleratio. 2015. Available online: https://circulareconomy.europa.eu/platform/en/knowledge/barriers-drivers-towards-circular-economy (accessed on 15 December 2021).

185. Bocken, N.M.; Olivetti, E.A.; Cullen, J.M.; Potting, J.; Lifset, R. Taking the circularity to the next level: A special issue on the circular economy. J. Ind. Ecol. 2017, 21, 476-482. [CrossRef]

186. Haas, W.; Krausmann, F.; Wiedenhofer, D.Y.; Heinz, M. How circular is the global economy? An assessment of material flows, waste production, and recycling in the European Union and the world in 2005. J. Ind. Ecol. 2015, 19, 765-777. [CrossRef]

187. European Commission. Closing the Loop-An EU Action Plan for the Circular Economy. The Circular Economy Package Proposal. 2015. Available online: https:/ / eur-lex.europa.eu/legal-content/EN/TXT/?uri=CELEX:52015DC0614 (accessed on 15 December 2021).

188. Moraga, G.; Huysveld, S.; Mathieux, F.; Blengini, G.A.; Alaerts, L.; Van Acker, K.; De Meester, S.; Dewulf, J. Circular economy indicators: What do they measure? Resour. Conserv. Recycl. 2019, 146, 452-461. [CrossRef] [PubMed]

189. Anthony, R.N.; Govindarajan, V.; Hartmann, F.G.; Kraus, K.; Nilsson, G. Management Control Systems; McGraw-Hill Education: London, UK, 2014.

190. Otley, D.; Soin, K. Management control and uncertainty. In Management Control and Uncertainty; Palgrave Macmillan: Londo, UK, 2014; pp. 1-13.

191. Salvioni, D.M.; Gennari, F.; Bosetti, L. Sustainability and convergence: The future of corporate governance systems? Sustainability 2016, 8, 1203. [CrossRef]

192. Salvioni, D.; Gennari, F. Stakeholder perspective of corporate governance and CSR committees. Symph. Emerg. Issues Manag. 2019, 28-39. [CrossRef]

193. Fornasari, T. Corporate social responsibility and ethics committees: A new form of embedding and monitoring ethical values and culture. Int. J. Curr. Res. 2018, 10, 74797-74802. 
194. Eccles, R.G.; Perkins, K.M.; Serafeim, G. How to become a sustainable company. MIT Sloan Manag. Rev. $2012,53,43$.

195. Ludwig, P.; Sassen, R. Which internal corporate governance mechanisms drive corporate sustainability? J. Environ. Manag. 2022, 301, 113780. [CrossRef]

196. Walker, S.; Coleman, N.; Hodgson, P.; Collins, N.; Brimacombe, L. Evaluating the environmental dimension of material efficiency strategies relating to the circular economy. Sustainability 2018, 10, 666. [CrossRef]

197. Sánchez-Ortiz, J.; Rodríguez-Cornejo, V.; Del Río-Sánchez, R.; García-Valderrama, T. Indicators to Measure Efficiency in Circular Economies. Sustainability 2020, 12, 4483. [CrossRef]

198. Dagiliene, L.; Frendzel, M.; Sutiene, K.; Wnuk-Pel, T. Wise managers think about circular economy, wiser report and analyze it. Research of environmental reporting practices in EU manufacturing companies. J. Clean. Prod. 2020, 274, 121968. [CrossRef]

199. Barnabè, F.; Nazir, S. Conceptualizing and enabling circular economy through integrated thinking. Corp. Soc. Responsib. Environ. Manag. 2021, 1-21. [CrossRef]

200. Aureli, S. Relevance and usage of management control systems with reference to strategy formulation and control: Evidence from Italian SMEs. In Handbook of Research on Strategic Management in Small and Medium Enterprises; Todorov, K., Smallbone, D., Eds.; IGI Global: Hershey, PA, USA, 2014; pp. 349-371.

201. Broccardo, L.; Giacosa, E.; Culasso, F.; Ferraris, A. Management control in Italian SMEs. Glob. Bus. Econ. Rev. 2017, 19, 632-647. [CrossRef]

202. Sgrò, F.; Palazzi, F.; Ciambotti, M.; Gelsomini, L. Factors promoting and hindering the adoption of management accounting tools: Evidence from Italian manufacturing SMEs. Manag. Control 2020, (Suppl. 1), 19-38. [CrossRef]

203. Netherlands Enterprise Agency. Circular Economy \& SDGs. How Circular Economy Practices Help to Achieve the Sustainable Development Goals. 2020. Available online: https:/ / circulareconomy.europa.eu/platform/sites/default/files/3228_brochure_ sdg_-_hch_cmyk_a4_portrait_-_0520-012.pdf (accessed on 3 November 2021).

204. O’Neill, D.W.; Fanning, A.L.; Lamb, W.F.; Steinberger, J.K. A good life for all within planetary boundaries. Nat. Sustain. 2018, 1, 88-95. [CrossRef] 